\title{
Metabolic Signatures of the Exposome-Quantifying the Impact of Exposure to Environmental Chemicals on Human Health
}

\author{
Matej Orešič ${ }^{1,2}\left(\mathbb{D}\right.$, Aidan McGlinchey ${ }^{1}\left(\mathbb{0}\right.$, Craig E. Wheelock ${ }^{3}\left(\mathbb{D}\right.$ and Tuulia Hyötyläinen ${ }^{4, *}$ \\ 1 School of Medical Sciences, Örebro University, SE-701 82 Örebro, Sweden; matej.oresic@oru.se (M.O.); \\ Aidan.McGlinchey@oru.se (A.M.) \\ 2 Turku Bioscience Centre, University of Turku and Åbo Akademi University, FI-20520 Turku, Finland \\ 3 Division of Physiological Chemistry II, Department of Medical Biochemistry and Biophysics, \\ Karolinska Institute, SE-171 77 Stockholm, Sweden; Craig.Wheelock@ki.se \\ 4 MTM Research Centre, School of Science and Technology, Örebro University, SE-701 82 Örebro, Sweden \\ * Correspondence: tuulia.hyotylainen@oru.se
}

Received: 8 October 2020; Accepted: 9 November 2020; Published: 10 November 2020

\begin{abstract}
Human health and well-being are intricately linked to environmental quality. Environmental exposures can have lifelong consequences. In particular, exposures during the vulnerable fetal or early development period can affect structure, physiology and metabolism, causing potential adverse, often permanent, health effects at any point in life. External exposures, such as the "chemical exposome" (exposures to environmental chemicals), affect the host's metabolism and immune system, which, in turn, mediate the risk of various diseases. Linking such exposures to adverse outcomes, via intermediate phenotypes such as the metabolome, is one of the central themes of exposome research. Much progress has been made in this line of research, including addressing some key challenges such as analytical coverage of the exposome and metabolome, as well as the integration of heterogeneous, multi-omics data. There is strong evidence that chemical exposures have a marked impact on the metabolome, associating with specific disease risks. Herein, we review recent progress in the field of exposome research as related to human health as well as selected metabolic and autoimmune diseases, with specific emphasis on the impacts of chemical exposures on the host metabolome.
\end{abstract}

Keywords: chemical exposure; disease biomarkers; exposome; human health; lipidomics; metabolomics; per- and polyfluoroalkyl substances

\section{Introduction}

It is currently widely recognized that combinations of environmental factors, interacting further with genetic factors, play crucial roles in human health and disease. Indeed, a majority of genome-wide-association studies (GWAS) have detected only relatively minor effects of common genetic variants on the incidence of most non-communicable diseases (NCDs) [1-3].

The exposome concept was first coined by Christopher P. Wild in 2005, when describing "the totality of human environmental exposures from conception onwards, complementing the genome" [3]. The exposome concept includes lifetime exposure, combining exogenous chemicals with genetic and other external factors that generate further molecular products inside the body and thereby may present threats to human health $[1,4-6]$. In this context, environmental factors comprise the full suite of general external, specific external and internal exposures $[7,8]$. General external exposures include the broader socioeconomic environment such as social capital, education level, built environment, urban-rural environment, and climate factors. Specific external exposures include an individual's external factors 
such as stress, specific contaminants, diet, physical activity, substance habits, allergens and infections. Internal exposures, on the other hand, include biological factors such as metabolism, the immune system, and the gut microbiome. It is understandably challenging to quantify these hyper-variable interdependent environmental and lifestyle factors because exposures are individual, have multiple sources with high complexity, and are dynamic.

Herein, we review recent progress in the field of exposome research as related to human health and selected metabolic and autoimmune diseases, with specific emphasis on the impacts of the "chemical exposome" (exposures to environmental chemicals) on the host metabolome.

\section{Exposomics Approach to Study Health and Disease}

Current chemical exposure assessments are still limited, with most of the reported studies covering a small fraction of chemicals to which humans are exposed. Any hypothetical total number of chemicals in the world is unknown, but over 140,000 and 86,000 chemicals have been registered for use in Europe and the USA, respectively [9]. This demonstrates the enormous number of chemicals, pollutants, and contaminants that humans may potentially be exposed to, the majority of which lack substantive data to perform comprehensive risk assessment. In addition, the assessment of exposure health risks is primarily based on studies involving individual chemicals or within chemical classes, or the use of various toxicological indices, which are themselves typically developed from studies using only single chemicals. This does not give a realistic overview of health risks, because mixtures of various chemicals may have a highly different impact on health than when taken in isolation. For instance, there is evidence suggesting that specific endocrine-disrupting chemicals compete with each other and with endogenous estrogens for access to metabolic enzymes and that this may lead to increased bioavailability of specific harmful chemicals [10]. Exposure to numerous chemicals could thus potentially have adverse effects at doses much closer to typical human exposures than previously assumed. Studies of chemical mixture exposure in humans (and children in particular) are therefore strongly warranted, when conducting quantitative risk assessments and determining regulatory exposure limits. While the main routes of human exposure to environmental chemicals for the general population include food, house dust, and drinking water in infants, occurrence of these compounds is attributed to placental transfer during fetal development, and breastfeeding. Moreover, in childhood, exposure via house dust can be an additional major source. In addition, exposure via airways and skin can be relevant to specific chemicals [11,12].

It should be emphasized that while screening pollutant profiles and their occurrence levels in humans or biota is important, this is not the most efficient way to characterize the health impacts of chemical exposures. Furthermore, the presence of a pollutant does not necessarily imply health impact. Not only does the screening approach require an enormous effort, but it does not account for individual variation in both the exposure and various critical biological factors. Exposure profiles are known to be strongly related to race/ethnicity, age, body mass index (BMI), as well as with several other social, environmental, and individual factors [13]. Furthermore, pollutant profiles in humans, if considered in isolation, would provide, at best, only incomplete health risk information compared to an analysis of chemical mixtures. A more efficient approach, therefore, is to employ a comprehensive analysis that covers both exogenous and endogenous compounds, including their metabolites. This approach, combined with health outcome data and accompanying metabolomics, i.e., comprehensive characterization of small molecule metabolic products (metabolites), can provide a tool for the identification of early biomarkers linked to exposure and, in turn, offer new opportunities in exposome research [14]. Measuring comprehensive chemical exposure profiles and investigating their respective associations with determinants of health status will enable an in-depth analysis of the links between these and result in more reliable conclusions.

The number of studies related to the exposome has markedly increased over the past decade [15-25]. A large number of epidemiological studies have sought to identify the associations between exposure to environmental chemicals and different chronic diseases, such as diabetes, cancer, and obesity [23,26-32]. 
Exposure studies using animal models have identified potential mechanisms, elucidating the impacts of various exposures on specific biochemical pathways. Chemical exposome studies are also emerging, integrating the profiling of exogenous and endogenous compounds with their impact on adverse health outcomes [33,34]. It should be noted, however, that there is a risk for obtaining false positive exposome-health associations due to the complex correlation structure of the exposome. It is very challenging (1) to efficiently untangle the exposures that causally impact specific health outcomes from spuriously associated exposures and (2) to identify synergistic effects between exposures. Therefore, it is crucial to give a careful consideration to both in the selection of appropriate statistical methods as well as to the interpretation of the results [35].

\section{Analytical Methodologies}

Characterization of the exposome requires the application of a diverse range of analytical techniques $[15-17,36,37]$. The methodologies required for exposome analysis as related to the study of chemical exposures include:

1. Analytical techniques for comprehensive chemical profiling (exogeneous and endogenous compounds);

2. Effect-directed analysis of the drivers of toxicity;

3. Advanced bioinformatics methods, in order to integrate the highly complex data and to identify effect-based markers of exposure.

Early exposome studies relied on the so-called "bottom-up approach", where the main sources of exposure (e.g., water, food, air) were screened for pollutants, followed by further analyses. The opposite, alternative approach is to start the screening in human samples, i.e., using the so-called "top-down approach", where chemical profiles are first associated with health status, and only later on the possible sources of exposures are linked with adverse health outcomes. The use of a "meet in the middle" (MITM) approach, which combines bottom-up and top-down approaches, has also been increasing [38]. This approach includes measuring intermediate biomarkers such as metabolites or other "omics" biomarkers, and retrospectively relating them to measurements of external exposure as well as prospectively to a specific health outcome. Specifically, the aim is to comprehensively characterize phenotypes in a human cohort setting, using multi-omics techniques (e.g., metabolomics, proteomics and transcriptomics) in order to identify specific adverse pathways affected by exposures and consequently driving disease risk. In the next step, in silico exploitation of (toxicological) databases and chemical bioactivity from high-throughput screening assays, reporter gene assays and docking studies can be used for the identification of pathway-associated exogenous and endogenous chemicals.

\subsection{Analytical Methods}

In order to comprehensively characterize the chemical profiles of the samples, analytical methods should cover both endogenous compounds (metabolites) as well as exogenous compounds, such as environmental pollutants. However, because the levels of many key metabolites are substantially higher than those of the environmental chemicals of concern (Figure 1), it is usually not possible to analyze all compounds within the same analytical protocols. In both cases, liquid or gas chromatography (LC, GC), combined with mass spectrometry (MS), is commonly used. Both LC and GC, combined with high-resolution mass spectrometry (HRMS) analyzers, including Orbitrap, Fourier transform ion cyclotron resonance (FT-ICR), time-of-flight mass spectrometry (TOF MS), and hybrid MS configurations, such as quadrupole-TOF (Q-TOF), ion-trap-TOF (IT-TOF), or quadrupole-Orbitrap (Q-Orbitrap) are used in exposome studies. In LC-based methods, soft ionization techniques such as electrospray or atmospheric chemical ionization are typically applied, while in GC-based methods, both hard (electron impact) as well as soft ionization (chemical ionization, atmospheric chemical ionization) are used. These methods can be applied with different acquisition modes including data-dependent acquisition (DDA), data independent acquisition (DIA) and all ion fragmentation (MS ${ }^{\text {all }}$ ). A combination of 
targeted, non-targeted, as well as suspect screening approaches, is typically applied in exposome analysis. Often, the environmental chemicals are analyzed with either target or suspect screening modes, while in metabolomics, non-targeted acquisition predominates. Specific metabolites may, however, require targeted strategies, either due to their low levels or their instability.

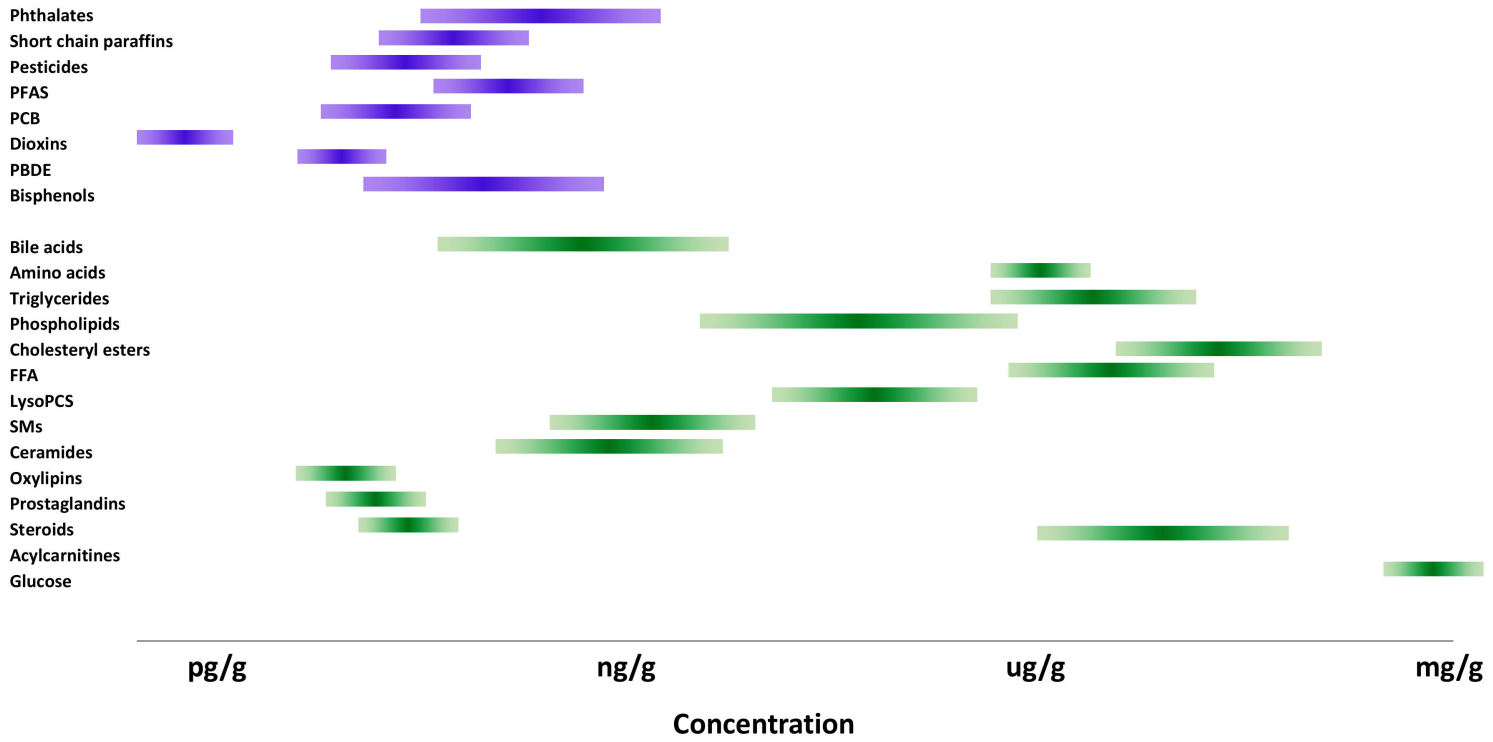

Figure 1. Plasma concentration ranges of the most common persistent organic pollutants (POPs) and metabolites.

There are several, established workflows described for untargeted metabolomics, most of which use at least two methods to cover both polar and non-polar metabolites. A majority of the methods are based on high-resolution mass spectrometric methods, combined with either LC or GC after very simple sample preparation, typically either by simple protein precipitation or by liquid extraction [17,39-43]. For the characterization of environmental pollutants, either in targeted, untargeted or suspect screening mode, more involved sample preparation methods are often required to remove the interfering compounds (e.g., abundant lipids). This is necessary in order to obtain sufficient sensitivity for the analysis. Larger amounts of sample are typically needed for the analysis of environmental contaminants as compared to metabolites and sample clean-up is required (e.g., liquid extraction, solid-phase extraction, phospholipid depletion). Most of the traditional methods are targeted analyses, again, mainly to obtain sufficient sensitivity, and the most common methods are based on GC-MS and LC-MS/MS. Recently, untargeted analysis and suspect screening approaches have been developed for the screening of the exogenous pollutants [44-48].

Reliable identification in the suspect screening and in untargeted analysis remains highly challenging. Large spectral libraries are available for GC-based methods and, in recent years, a major effort has been undertaken to compile LC-based spectral libraries. Unsupervised and supervised machine learning approaches can be utilized in the identification of unknown compounds. For example, using an unsupervised algorithm, MS2Analyzer combines structural information inherent to product ions and their fragments, neutral losses and isotopic ratios, with literature-derived neutral loss/substructure pairs to detect the presence of the same or similar substructures [49]. Supervised machine learning classification methods can be applied for the detection of specific substructures or structural neighbors according to the presence of predefined substructures and classification of unknowns accordingly [49-51] or for the determination of spectral features. Direct structure elucidation methodologies can also be applied using general fragmentation rules using, e.g., the publicly available MS-FINDER [52] software. However, fragmentation can often be unpredictable, and structurally similar compounds do not always generate similar fragments. These approaches do generally work, however, 
for specific types of compounds, such as lipids. Several approaches using various indirect structure elucidation approaches as well as in silico spectral prediction approaches have been developed [53-57]. In untargeted analyses, it is possible to utilize the unique mass spectral features of, e.g., halogenated compounds, so that it is possible to screen these compounds based on the mass spectrum. Particularly in GC-MS based methods, it is possible to use compound classification based on mass-spectral fragmentation patterns. These procedures have been developed for various environmental samples and for metabolomics [58-60], although they have rarely been applied in exposome analysis to date.

\subsection{Data Analysis}

Increasing levels of detail and increased understanding of the interconnected nature of various levels of biological organization form both the basis and a key objective of taking the holistic approach that is systems medicine. This is of particular relevance in exposome research, because complex and often subtle effects with subsequent knock-on effects occur up and down the different levels of organization within organisms, including humans. Appropriate methods are therefore required to meaningfully tease apart changes of interest across multiple levels of high-throughput data, bringing together exposure data (being often high-dimensional) with various other strata of data (e.g., metabolomic, proteomic, lipidomic, transcriptomic or otherwise).

A first and crucial step in data analysis for exposome and metabolomics research is pre-processing of the data (e.g., via log transformation, scaling to zero mean and unit variance in the case of metabolomics data) rendering the measured levels of metabolites/chemical exposure of interest amenable to correlation, or other associative, analyses to search for relationships.

In exposome analysis, therefore, both appropriate pre-processing and data integration techniques are crucial, both in the case of (1) integrating exposome data with high-dimensional, multi-omics data, and (2) when investigating the effects exposure to complex chemical mixtures, in order to identify biomarkers of said exposure. Further, given that exposure data from the general populace is inherently heterogenous, this presents a further layer of complexity that also must be dealt with, either at the level of study design, or with appropriate statistical or machine learning methods.

Regarding exposure data in particular, it is now well-recognized in the field that, when translating the impacts of chemical exposures to measurable health outcomes, one needs to model such exposures as mixtures, rather than only as single effects and doses. This poses methodological challenges that are still being debated in the field [61]. Typically, the impact of exposure to mixtures of agents on specific outcome variables is modelled with a regression approach. Many statistical/machine learning methods lend themselves to this purpose, and these are extensively reviewed and assessed by Agier et al. [61]. Among these, particularly Bayesian kernel machine regression (BKMR) is a popular choice for estimating the health effects of chemical mixtures [62], but, as is also the case for most other methods, its use is limited to estimation of an effect on a single outcome variable at a time, rendering it unsuitable for application to complex phenotypic data (e.g., multi-omics data or where more than one clinical outcome may be affected by exposure to the mixture).

In the case of complex, multi-variate or multi-modal outcomes, one data analysis strategy is to combine regression approaches with network analysis [34]. In such an approach, chemical exposure data, along with multi-modal phenotypic data (dimensionality reduced, e.g., by model-based clustering [63], if necessary or applicable) are brought together and analyzed by first applying partial correlation network analysis. This involves first the crucial step of rejecting likely spurious correlations, e.g., through the calculation of non-rejection rates as available in openly available packages for the $\mathrm{R}$ statistical programming language, such as the qp-graph package [64]. Based on this analysis, a network of interacting components between (1) the exposome, (2) intermediary layer(s) of (potentially also dimensionality-reduced) data (e.g., metabolomics or other -omics), and (3) the various clinical outcomes of interest can be projected and subsequently both analyzed and meaningfully interpreted holistically. Further, "connected" outcome variables of interest can then be selected, and regression analyses performed linking chemical mixtures with outcome variable(s) of interest (e.g., by iterative 
ridge regression modelling using bootstrapping [34]). Such an examination of the network can (1) help identify key phenotypic variables of interest by removing spurious associations, and (2) provide predictive and relative contributions of individual chemicals towards the variable(s) of interest.

Further, with the striking rise in the application and development of machine learning methods, great potential exists for its application to exposome research, enabling robust interrogation of large, multi-omics datasets to ascertain key factors affecting real-world health outcomes in data from both purely experimental settings as well as from the harvesting of population data.

With increasing computational power and software available to researchers, the possibility now exists for thorough mining of exposome data to link complex mixtures of exposures to not only clinical outcomes, but to assist in the elucidation of key mechanisms occurring at the various biological levels of organization and information flow between exposure and health effects. Appropriately, methods such as multi-layer (deep) artificial neural networks (ANNs) are proving to be of striking utility across a plethora of fields for analyzing high-dimensional, heterogeneous data for purposes of classification (e.g., health outcome) and regression type analyses (e.g., exposure effect on markers of interest). ANNs and associated deep learning methods currently suffer from issues of interpretability and are difficult to apply to the development of simpler clinical tests; other machine learning methods, such as the random forest, can currently provide clearer answers regarding the importance of the features that they use and divulge thresholds by which the models make their best-performing classification methods, forming the basis of direct translation to clinical testing. Machine learning and its application to metabolomics and multi-omics data are reviewed in detail elsewhere $[65,66]$.

The ability to generate a meaningful, robust and multi-layered overview of biological effects from exposure to a mixture of agents addresses an unmet need in exposome research. This is a notable step for the field, clearly showing, for example, networks of interacting factors from heterogeneous, multi-omics data for downstream analysis, biomarker discovery and toxicity threshold testing of real-world mixtures of agents, which may behave markedly differently from more simplistic approaches that take such exposures as single factors.

\section{Metabolic Markers of Exposure to Environmental Chemicals}

The metabolome in exposome studies can be considered as an intermediate phenotype, linking exposures with health status [67]. Metabolic changes observed in exposome studies may thus provide clues about the changes in adverse outcome pathways, potentially linked to specific diseases (Figure 2). Whilst the number of studies wherein metabolomic profiles are associated with exposures in human cohorts is increasing, their overall number remains limited, providing information mainly only on specific chemical groups [24,25]. In addition, many of these studies involve only a small number of participants, using analytical methods with limited coverage of the metabolome. On the other hand, the challenge with in vivo and in vitro models is, however, that often the doses used in the experiments may not accurately reflect the true environmental concentration levels. Below, we review current knowledge about the impacts of chemical exposures on human metabolome. 


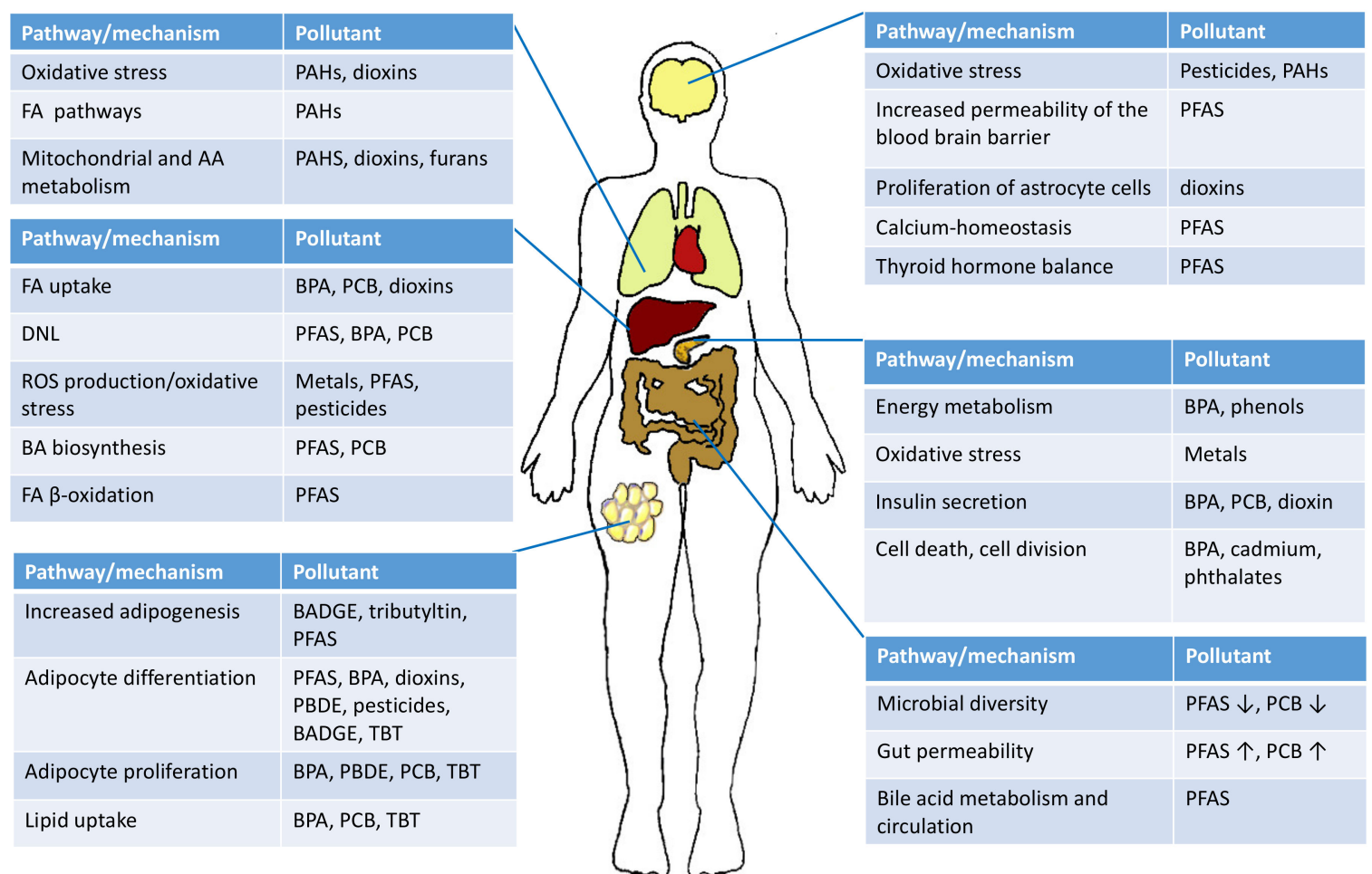

Figure 2. Reported impacts of exposure to environmental chemicals on metabolism.

\subsection{Lipid Metabolism in Liver and Adipose Tissue}

Several environmental chemicals have been found to impact lipid metabolism, including metals, polycyclic aromatic hydrocarbons (PAHs), per- and polyfluoroalkyl substances (PFASs) and polychlorinated biphenyls (PCBs).

At the organ level, the two main organs involved in lipid metabolism are the liver and adipose tissue (AT). The liver is the largest and most metabolically complex organ in the human body, while AT is the key regulator of energy balance and nutritional homeostasis [68]. Adipocytes also regulate body weight, are an important site for the synthesis of estrogen and store steroid hormones in addition to playing a role in immune responses. AT can store a variety of hydrophobic chemicals, in particular persistent organic pollutants (POPs), and thus it constitutes a low-grade internal source of stored POPs, leading to continuous exposure in other tissues $[69,70]$. Moreover, xenobiotic compounds may alter AT functions, increase AT inflammation, and/or modulate differentiation of AT precursor cells [70].

Several pollutants have been shown to significantly alter the function (gene expression, hormone secretion) of white AT, AT mass (adipocyte number and/or volume), or body weight in animal models after developmental exposure [71-75]. In particular, tributyltin (TBT), phthalates, bisphenol A (BPA), diethylstilbestrol (DES), polyaromatic hydrocarbons (PAHs) and parabens have been shown to possess obesogenic properties [76-79]. These compounds can act through several pathways that promote adipogenesis and lipid accumulation. For most compounds classified as obesogens, prenatal exposure results in an increased number of adipocytes [80]. The main mechanism involved in adipogenesis acts through PPAR $\gamma$ function.

PCB153 has been shown to induce substantial alterations in levels of glycerophospholipids and sphingolipids in vitro [81,82]. Similar results were also observed in human studies [83]. Short-chain chlorinated paraffin studies have been shown to impact lipid metabolism in vitro through stimulation of $\beta$-oxidation of unsaturated fatty acids and long-chain fatty acids [84].

Metal exposure, such as to cadmium, lead or arsenic, has been suggested to cause increased lipid peroxidation [18,85-87]. Combined exposure to lead, cadmium and arsenic showed disturbances in energy metabolism, more precisely, changes in lipid fraction, unsaturated lipids and in the level of amino 
acids suggesting perturbation of lipid metabolism and amino acid metabolism [87]. Exposure to PAHs has been shown to have a marked impact on urinary metabolic profiles, and the metabolic outcomes of PAH exposure were generally associated with metabolites related to lipid metabolism, indicative of an oxidative stress response [88]. Chlorinated compounds such as dioxins, PCBs, organochlorine insecticides and trichloroethylene (TCE) have been shown to trigger similar metabolic changes as in PAHs and metals, but generating an even more substantial impact on lipid metabolism, including cholesterol metabolism, sphingolipid metabolism and bile acid (BA) biosynthesis, confirming their potential to induce chronic diseases such as atherosclerosis, diabetes or obesity [89-92].

A recent animal model study showed that dichlorodiphenyldichloroethylene (DDE) exposure leads to down-regulation of phosphatidylcholines (PCs), phosphatidylethanolamines (PEs), phosphatidylserines (PSs), and up-regulation of diacylglycerols (DGs), while triacylglycerols (TGs) were found both increased and decreased as a result of exposure, depending on the specific molecular species in question [93]. The study also indicated a potential role for gut microbiota-lipid interactions, as 17 bacterial species associate with lipids with notable correlations (Bacteroidetes, Firmicutes, Proteobacteria and Tenericutes, and DG, PC, PE and TG).

In a Swedish cohort of elderly subjects, circulating levels of $\mathrm{p}, \mathrm{p}^{\prime}$-DDE and hexachlorobenzene (HCB) levels were linked to a set of lipid-related metabolites involved in key metabolic processes such as cell signaling, energy regulation, and membrane composition (e.g., fatty acids and different classes of glycerophospholipids) [25]. The study also suggested that there may be differences in the lipid pathways impacted by the two organochlorine pesticides. Another study showed similar associations between the levels of DDE, $\beta-\mathrm{HCH}, \mathrm{HCB}, \mathrm{PCBs}$ and lipids, particularly in specific sphingolipids and glycerophospholipids [83]. The limitations of both of these studies was that the metabolomics analyses did not cover TGs and the most polar metabolites.

PFASs were also found to have an impact on lipid metabolism and energy metabolism [94,95]. In a recent study of 1000 elderly people in Sweden, 15 metabolites, predominantly from lipid pathways, were associated with levels of PFASs, following adjustment for sex, smoking, exercise habits, education, energy, and alcohol intake [24]. Perfluorononanoic acid (PFNA) and perfluoroundecanoic acid (PFUnDA) were strongly associated with multiple glycerophosphocholines and fatty acids, including docosapentaenoic acid (DPA) and docosahexaenoic acid (DHA) [24]. However, as dietary data were not available, some of the associations may be related to dietary factors, such as the intake of fish products, given that one of the main sources of PFAS in the Nordic population is fish intake, which has a somewhat similar impact on human levels of polyunsaturated fatty acid (PUFA)-containing lipids. These results indicate that the different PFASs evaluated were associated with distinctive metabolic profiles, suggesting potentially different biochemical pathways in humans. Perfluorooctanoic acid (PFOA), a widely used PFAS, was also found to be significantly associated with elevated uric acid in several studies $[24,96]$. Uric acid is an important metabolite in purine metabolism, and several epidemiologic studies, supported by studies in animal models, indicate that elevated uric acid is a risk factor for hypertension and possibly an independent risk factor for stroke, diabetes, and metabolic syndrome $[97,98]$.

\subsection{Bile Acids}

BAs are metabolites that facilitate the digestion and absorption of lipids in the small intestine and they are also important metabolic regulators involved in the maintenance of lipid and glucose homeostasis [99,100]. BA metabolism is also closely linked with gut microbiota, which plays an essential role in the deconjugation of primary BAs and secondary BA synthesis. Exposure to POPs, such as PFAS and PCBs, has been shown to result in changes in the composition of the gut microbiota [101,102]. Several pollutants have shown to modulate BA metabolism, including PFAS, dioxins, and PCBs [95,102-105].

PFAS can have an impact on BA metabolism at several levels (Figure 3). For example, PFAS can inhibit 7-alpha-hydroxylase (CYP7A1), which catalyzes the first and rate-limiting step in the formation of BAs from cholesterol $[30,106]$. This may lead to increased re-uptake of BAs, which would generate 
negative feedback loops via the farnesyl-X-receptor (FXR) and subsequently reduce their de novo synthesis. PFOA also inhibits the function of hepatocyte nuclear factor $4 \alpha$ [107], which plays a central role in the regulation of BA metabolism in the liver and is linked to both the synthesis and conjugation of primary BAs. The liver clears most BAs via sodium taurocholate co-transporting polypeptide (NTCP), and several PFAS are also substrates for human NTCP [95]. PFAS exposure also alters the composition of the gut microbiota [101-103,108-110], which, in turn, can cause alteration in the pool of secondary BAs. Associations observed between PFAS and BAs are potentially important for our understanding of cardiometabolic diseases, given that BA metabolism is known to play a role in the pathogenesis of type 2 diabetes (T2D), atherosclerosis and non-alcoholic fatty liver disease (NAFLD) [111].

PCB exposure has been shown to modify the gut microbiota composition also and modulate BA homeostasis in conjunction with host BA processing genes in a dose- and bio-compartment-specific manner [103]. Current studies also indicate that PCBs modulate signaling within both neurons and epithelial cells, supporting the hypothesis that exposures may detrimentally impact the gut-brain axis [110].

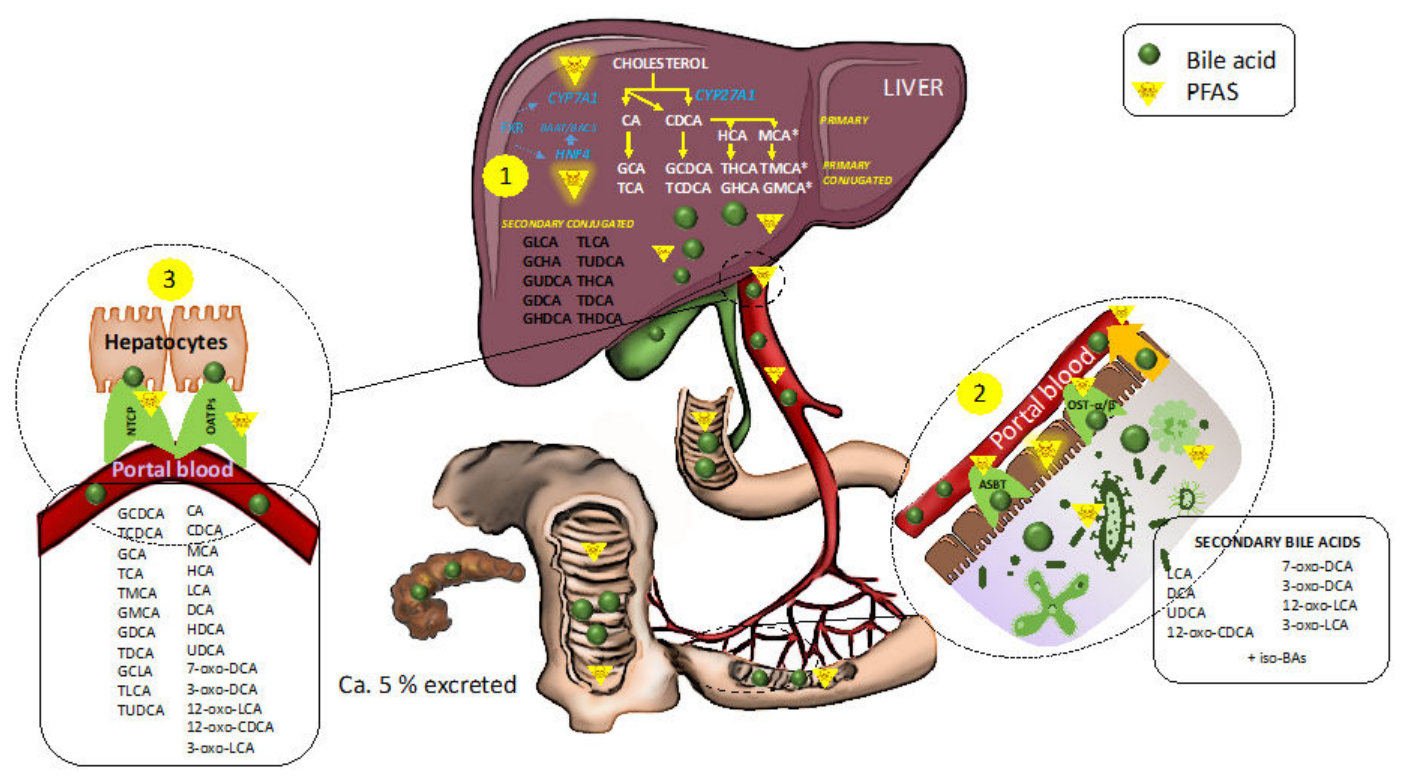

Figure 3. Bile acid biosynthesis and enterohepatic circulation, and the impact of polyfluoroalkyl substances (PFASs) on bile acid (BA) metabolism. (1) In the liver, the classic BA synthesis pathway is initiated by cholesterol $7 \alpha$-hydroxylase (CYP7A1) which is downregulated by PFAS. The alternative BA synthesis pathway is initiated by CYP27A1 to synthesize primary bile acids, CA and CDCA, in hepatocytes. CDCA can be further converted to HCA and MCA in the liver. CYP7A1 is downregulated by PFAS. Bile acids are conjugated to the amino acids taurine or glycine before being released into the intestine. HNF $4 \alpha$, which plays a central role in bile acid conjugation by direct regulation of VLACSR and BAAT, can be suppressed by PFAS. (2) BAs are recovered into portal blood through a combination of passive absorption in the proximal small intestine, active transport via apical bile salt transporter (ASBT) in the distal ileum, and passive absorption in the colon and via organic solute transporter $\alpha / \beta(\mathrm{OST} \alpha / \beta)$. Perfluorooctanesulfonic acid (PFOS) can also be transported by ASBT and OST $\alpha / \beta$. Furthermore, PFAS can increase the permeability of the gut, thus impacting the passive transport pathway of BAs. In the colon, BAs are also deconjugated by bacterial bile salt hydrolase and are $7 \alpha$-dehydroxylated by bacterial $7 \alpha$-dehydroxylase to form secondary BAs. PFAS can modify gut microbial composition and thus impact microbial BA formation. (3) BAs are eventually recycled from portal blood back to hepatocytes via Na-taurocholate co-transport peptide (NTCP) and the sodium-independent organic anion transporting polypeptide (OATP). PFASs also utilize the NTCP and OATP transporter. The majority (90-95\%) of BAs secreted into the small intestine are actively reabsorbed in the terminal ileum and circulate back to the liver while ca. $5 \%$ are excreted via feces. 


\subsection{Amino Acid Metabolism}

Metals, plasticizers and other organic pollutants have been associated with altered amino acid metabolism. Exposure to cadmium, lead and arsenic has been suggested to cause various oxidative stress-related effects, including the depletion of antioxidants, accelerated muscle proteolysis, elevated activity of UDP-glucosyltransferases (UGTs) [18,85-87]. Specifically, cadmium exposure has been associated with metabolites related to amino acid metabolism, galactose metabolism, purine metabolism, the creatinine pathway as well as with steroid hormone biosynthesis [85]. Combined exposure to lead, cadmium and arsenic showed perturbation of the metabolism of amino acids [87]. Short-chain paraffins have been shown to disturb glycolysis and amino acid metabolism, leading to the up-regulation of glutamate metabolism and the urea cycle [84].

BPA exposure, as summarized in a recent review [112], is associated with alteration of branched chain amino acid metabolism, aromatic amino acids metabolism and sulfur-containing amino acid metabolism. Particularly, alterations to phenylalanine metabolism, tryptophan metabolism, tyrosine metabolism, lysine degradation, and arginine biosynthesis has been observed in female infants while male infants were less affected [113].

Exposure to PAHs has been associated with metabolites related to amino acid and purine metabolism, indicative of an oxidative stress response [88]. Altered amino acid metabolism has also been associated with PFAS exposure, particularly with regards to tyrosine metabolism [114]. Another study identified a positive association between PFAS exposure and phosphoethanolamine, tyrosine, phenylalanine, aspartate and creatine, and inverse association with betaine [115].

Altered amino acid metabolism is linked with several diseases, including diabetes, obesity and NAFLD. Increased levels of aromatic amino acids, such as tyrosine and phenylalanine, have been consistently found to be closely associated with hyperglycemia, insulin resistance and risk of type 2 diabetes [116-119].

\subsection{Energy Metabolism and Oxidative Stress}

Exposure to environmental chemicals, particularly to PAHs and metals, has shown to increase reactive oxygen species (ROS)—mediated oxidative stress in several studies [120,121]. Similarly, environmental chemical exposure has been shown to cause disruption of the tricarboxylic acid (TCA) cycle, thus impairing mitochondrial function and energy production [122].

Exposure to airborne pollution, including black carbon, carbon monoxide, nitrogen oxides and fine particulate matter, which most likely contains a large number of different organic contaminants, was linked with aggravation of inflammatory and oxidative stress-related pathways, including leukotriene and vitamin E metabolism [123].

Metabolic changes induced by phthalates affect both anti-oxidant mechanisms (mitochondrial beta-oxidation, amino acid metabolism) and disrupt prostaglandin-regulated pathways [124-126]. A recent study further showed that exposure to mono-n-butyl phthalate (MnBP) was associated with being overweight/obesity in children and elevated MnBP concentrations in urine correlated with global urine metabolic abnormalities as characterized by disrupted arginine and proline metabolism, increased oxidative stress and fatty acid re-esterification [126].

\subsection{Impact of Environmental Exposure on Metabolome via Gut Microbiota}

In addition to direct impacts of exposures on host metabolism, the exposures may also alter host metabolism indirectly, e.g., via gut or even skin microbiota. Exposure to environmental pollutants may cause adverse changes in the composition of the gut microbiota, resulting in gut dysbiosis. Moreover, such exposure can even alter the metabolic capacity of the gut microbiota, affecting the production of bacterial metabolites, which, in turn, may lead to adverse health effects in the host. However, many alterations of the gut microbiome composition can be secondary consequences of toxic effects 
acting on other organs and organ systems, and as such these effects should not be considered as only a direct effect on the gut microbiota.

A recent review by Jin et al. summarized the impact of different pollutants on the gut microbiota [127], showing that exposure can lead to various alterations in the gut microbiota favoring the growth of pathogenic bacteria whilst proving deleterious to beneficial bacteria. For example, a recent murine study showed that DDE induces gut dysbiosis as indicated by way of an increased Firmicutes-to-Bacteroidetes ratio, which may impact energy harvest efficiency [93]. A study in humans, on breast-fed infants, showed that POP exposure again impacted the gut microbiota, specifically, both PBDE-28 and the surfactant perfluorooctanesulfonic acid (PFOS), another widely used PFAS, were associated with reduced microbiome diversity [108]. Moreover, toxicants in breast milk affected microbiome functionality, explaining over $30 \%$ of variance in the levels of two short-chain fatty acids (acetic and propionic acids). Alterations in bacterial metabolism due to exposure have also been shown to cause bile acid dysmetabolism [128,129]. Chemical exposure may also negatively affect epithelial cells and so give rise to increased gut permeability and infiltration of the lamina propria by bacterial metabolites, pollutants, and pathogenic bacteria [130]. Consequently, this dysbiosis, in conjunction with the resulting modulation of the gut immune response and systemic inflammation, could result in the development of several diseases, including T2D, obesity, inflammatory bowel disease, and neurobehavioral dysfunction due to disruption of the gut-brain axis [67].

\section{Health Impacts of Environmental Exposure}

There are several studies linking environmental exposure to various diseases, including pre-eclampsia, congenital heart defects, fetal growth restriction, chronic fatigue syndrome, cancer, colonic polyps, respiratory disease, obesity, and diabetes $[4,5,26,31,126,131-151]$ (Figure 4). However, it should be emphasized that in most exposome studies, only targeted analyses of specific chemicals have been carried out, and the role of combined exposures as a mixture of multiple chemicals and the metabolome has not yet been systematically studied. Although there are several studies linking metabolic changes with exposure, most of these studies have not characterized the metabolome comprehensively, but instead used clinical metabolic values, such as glucose, insulin, and clinical lipid markers. On the other hand, several metabolic biomarkers have been identified for different chronic diseases. These biomarker profiles could also be used as adverse health outcome markers, when the actual health outcomes are not known. This is particularly important in the cases where disease development is still in its early, prodromal stages, e.g., in prediabetic subjects. Furthermore, understanding the early molecular events along the exposure-disease continuum will provide valuable information that may be used to develop intervention and prevention strategies. As already discussed above, it is also crucial to critically examine if the found exposome-health associations reflect potential causal relationships, or spurious associations.

Below, we review the studies linking chemical exposures, metabolic markers, and selected health outcomes, including as related to early development, metabolic and autoimmune diseases (type 1 diabetes). 


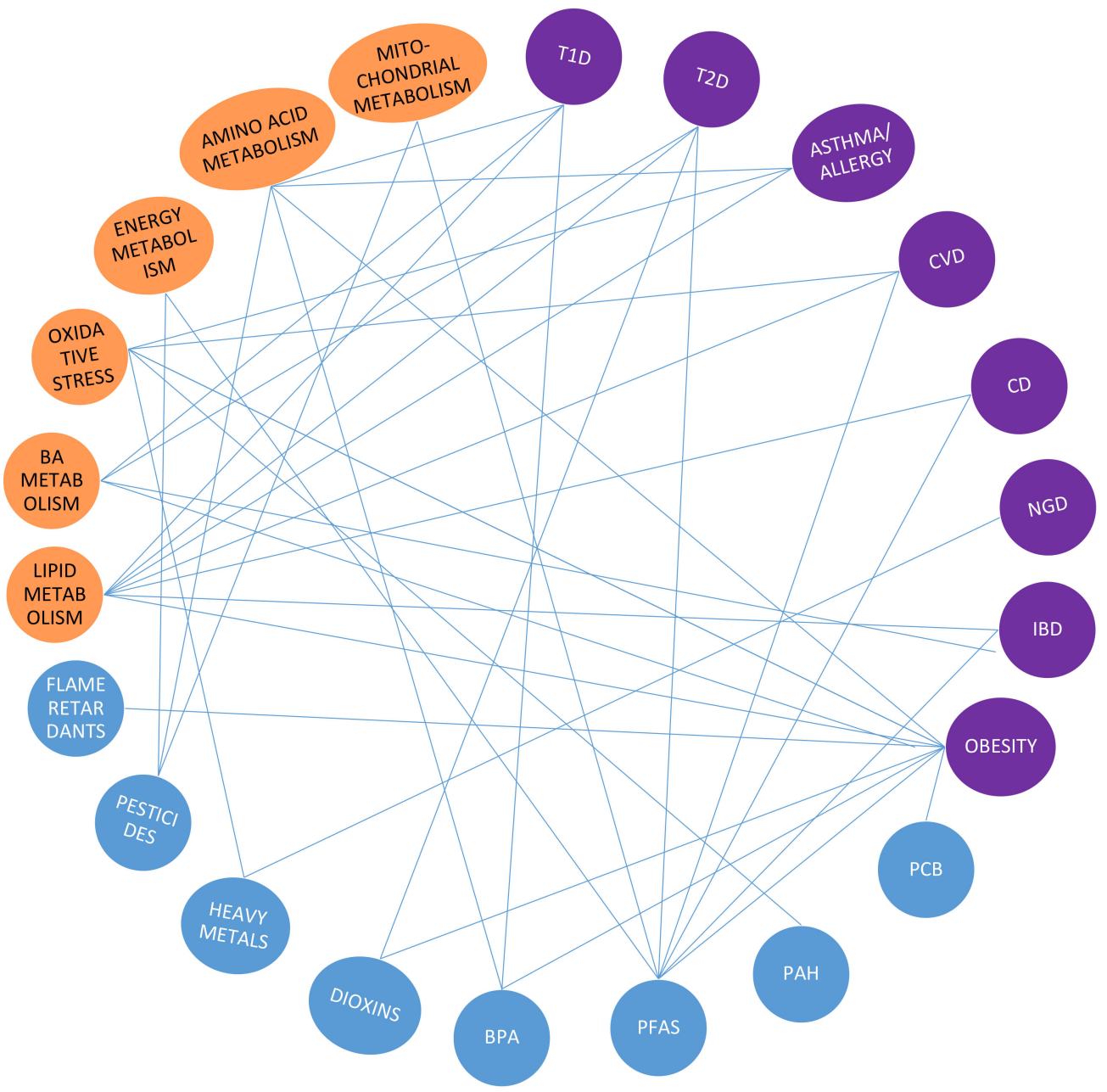

Figure 4. Reported associations between exposure (blue circles), specific diseases (violet circles) and metabolic pathways (orange circles).

\subsection{Exposures during Early Development}

Metabolomics can be utilized to characterize internal exposures or health status during pregnancy. Phthalates, bisphenols and PFAS have been reported to have an influence on childhood growth. Specific lipids, including fatty acid metabolites, amino acids and a steroid have been identified as potential biomarkers of "small for gestational age" during pregnancy, indicating potential dysregulation of lipid pathways in the placenta. However, any association with maternal health status remains unclear [152]. Maternal urinary levels of branched-chain amino acids and steroid hormone by-products were found to be strongly predictive of birth weight [153], while several circulating metabolites have also been associated with birth weight, including lysophospholipids [154,155]. Maternal smoking during pregnancy is known to have several adverse health effects on the offspring, including lower birth weight and other health impacts later in life. Maternal smoking has been associated with alterations of the fetal metabolome, particularly phospholipid profiles [156]. In experimental models, prenatal exposure to BPA caused significant changes in metabolites associated with lipid, BA, amino acid, and glucose metabolism [112,157-159].

There are several reports on the impact of PFAS exposure during fetal development and early life on the health outcome of children, with PFAS exposure being associated with cardiometabolic risk factors including reduced birth weight, reduced birth length, and increased adiposity. However, the results of such studies have been inconsistent $[139,142,160,161]$. Whilst many of these risk factors have been associated with alterations in the metabolome, it is still not clear whether the effects of PFAS on 
health endpoints are mediated by metabolic disturbances. As reviewed recently [162], most studies report association between reduced birth weight and PFAS exposure [163-167], although there are also studies reporting no significant association [168]. It has been suggested that the reduced birth weight could be attributed to maternal lipid changes following on from exposure, as PFOS levels were associated with reduced levels of polyunsaturated fatty acids in pregnant women, and the changes were further associated with reduced birth weight in female infants [169]. Several studies also identified associations of PFAS with increased body weight later in life $[135,166,170]$, as well as with higher insulin levels [171], although contradictory results have also been reported [172]. PFOA levels in childhood were found associated with lower pancreatic $\beta$-cell function in adolescence [135]. PFAS exposure in childhood has also been associated with dysregulation of several lipid and amino acid pathways, as well as longitudinal alterations in glucose homeostasis in overweight and obese children [114].

\subsection{Type 2 Diabetes, NAFLD, Obesity, and Metabolic Syndrome}

Several studies in human cohorts have shown association between chemical exposure and T2D [173].

A negative association has been observed between serum concentrations of PCB-118, $\beta-\mathrm{HCH}$ and specific PFAS with lobular inflammation in the liver [29,174].

PFAS exposure was found associated with metabolic diseases such as diabetes, being overweight/obese and heart diseases, with the strongest association reported across different studies being dyslipidemia. According to a recent review, there is relatively consistent evidence of modest positive associations between PFAS exposure and lipid profiles, such as total cholesterol and triglycerides, although the magnitude of the cholesterol effect is inconsistent across different exposure levels [175]. A study of Danish children studied the association of PFOS and PFOA with clinical metabolic markers (blood glucose, insulin, triglycerides, adiponectin and leptin), and found that, in overweight children, high PFAS levels were associated with elevated insulin levels, $\beta$-cell activity, insulin resistance, and TGs. There was no such association in normal-weight children [148]. Another study, with 74 children with NAFLD and a control group (age 7-19 years) showed that higher PFAS exposure was associated with more severe disease in children with NAFLD, indicating that PFAS may be an important toxicant contributing to NAFLD progression [115].

A study of elderly Swedes found that perfluorononanoic acid (PFNA) was related to prevalent diabetes in a non-monotonic fashion, suggesting an influence on glucose metabolism in humans at the level of exposure seen in the general elderly population. In the same study, PFOA was also associated with insulin secretion, although none of the measured PFASs were associated with insulin resistance [23]. Another study investigated the associations of four PFASs (PFOA, PFNA, PFOS, and perfluorohexane sulfonic acid-PFHxS) with cholesterol, body size, and insulin resistance, identifying positive associations between both PFOS and PFOA with cholesterol, but not insulin resistance or body size [143].

PFAS exposure was found associated with various measures of blood glucose and cholesterol in several studies $[23,176]$. Using cross-sectional data from 7904 adults (age $\geq 20$ years) in the National Health and Nutrition Examination Survey (NHANES), a strong positive association between serum PFOA and diabetes prevalence in men was identified, and the highest PFOA levels were linked with serum total cholesterol in both males and females [176]. In a recent prospective, a nested case-control study in the USA, clinical metabolic markers (cholesterol, triglycerides, adiponectin, $\mathrm{HbA1c}$ and insulin) were studied together along with the levels of five PFASs (PFOS, PFOA, PFHxS, PFNA, PFDA) [26]. The results showed that high plasma concentrations of PFOS and PFOA were associated with an elevated risk of T2D. Another study found that PFOS and PFOA were associated with insulin resistance, $\beta$-cell function, and $\mathrm{HbA1c}$. After 4.6 years of follow-up, however, these chemicals did not appear to affect the incidence of diabetes or changes in these markers [177]. 


\subsection{Type 1 Diabetes}

The incidence of several (auto)immune diseases has been increasing in many industrialized countries since 1950s [178]. Among them, the highest increase in incidence of type 1 diabetes (T1D) was observed among children under five years of age [179]. While several non-exclusive hypotheses have been proposed, aiming to explain these incidence trends, their underlying causes are still poorly understood. T1D is an autoimmune disease caused by destruction of insulin-secreting pancreatic $\beta$-cells [180]. The strongest genetic risk factors for T1D are found within the human leukocyte antigen (HLA) gene complex, yet only $3-10 \%$ of individuals carrying HLA-conferred disease susceptibility develop T1D [162]. The important role of environmental factors, including gene-environment interactions, is thus obvious [181]. For unknown reasons, T1D incidence has stabilized in the last decade, particularly in the Nordic countries [182].

Environmental triggers and specific co-morbidities are often implicated in T1D, e.g., enterovirus infection, diet, and obesity [181]. However, obesity has not shown a concomitant decrease since 2005 [183], and severe enterovirus infections in Finland during the period 2006-2010 increased, in fact, by 10-fold [182]. However, the time trend of human exposure levels to PFOS and PFOA does follow T1D incidence. The use of PFOS and PFOA has increased substantially since production started in the 1950s, until the main, global manufacturer ceased production of PFOS, PFOS-related substances and PFOA between 2000 and 2002. In the EU, all uses of PFOS were banned in 2008.

PFASs are potentially immunotoxic, thus capable of either suppressing the immune system or promoting the development of autoimmune diseases [184]. Recently, the National Toxicology Program reported that, "PFOA is presumed to be an immune hazard to humans based on a high level of evidence that PFOA suppressed the antibody response from animal studies and a moderate level of evidence from studies in humans" [185]. Currently, the information on the environmental chemicals as possible triggers of T1D is limited. However, it is plausible that they can contribute to T1D development via impaired pancreatic $\beta$-cell and immune-cell function and immunomodulation [133]. It has, for example, been shown that PFOA and PFOS disrupt the generation of human pancreatic progenitor cells [186]. Studies in human cells, i.e., those showing perturbation of the generation of pancreatic precursors caused by PFOA and PFOS, suggest that these compounds might compromise the formation of the mature pancreas, which would result in increased risk for T1D. Moreover, epidemiologic studies have identified a link between exposure to PFOA and PFOS and the occurrence of diabetes, dysfunctions in sugar metabolism, and insulin secretion $[135,187]$. Epidemiological studies also report immunosuppressive effects of PFAS, increased risk of infection in early childhood and association with immunotoxic effects $[139,145]$. Recently, elevated levels of PFOS in T1D patients compared to controls was reported [145]. There is a general consensus that exposure to PFOA and PFOS alters the immune system in experimental models, with documented effects including alteration of antibody and cytokine production [188]. Despite this, there remain contradictory studies related to PFAS exposure and T1D and beta-cell autoimmunity, both in epidemiological studies as well as animal models. While most studies have found positive associations between exposure to PFAS and diabetes, autoimmune responses and glucose homeostasis $[132,133,135,145]$, there are also a few studies that show no associations of $\beta$-cell autoimmunity and exposure [189], or even a negative association between diabetes and PFAS levels [187]. These contradictory results may be explained by several factors, potentially including differing coverage of PFAS substances, differences in the levels and length of time of exposure in the studies. In vitro and animal models have shown a non-monotonic dose-response of PFAS [132], and this, in combination with differences in, e.g., genetic risk factors, may explain some of the observed differences. Of the other PFASs, PFNA has, in animal studies, been shown to have toxic effects on lymphoid organs, T-cell and innate immune-cell homeostasis, suggesting that these effects may result from the activation of PPAR $\alpha, \operatorname{PPAR} \gamma$, and the hypothalamic-pituitary-adrenal axis [190]. In a non-obese diabetic (NOD) mouse model, prenatal and early life exposure to perfluoroundecanoic acid (PFUnDA) was shown to increase pancreatic insulitis (inflammation development, a prerequisite 
of diabetes development). There was a demonstrable increase in the number of apoptotic cells in pancreatic islets prior to insulitis and decreased phagocytosis in peritoneal macrophages [132,133].

Children progressing to T1D-associated islet autoantibody positivity, or to overt T1D later in life, show a distinct serum lipidomic profile characterized by decreased blood phospholipid levels, including sphingomyelins (SMs), within the first months of life, preceding the onset of islet autoimmunity [191]. These findings, first reported in 2008, have since been confirmed in multiple studies [192], including, most recently, the multinational The Environmental Determinants of Diabetes in the Young (TEDDY) cohort [193]. Notably, these pre-autoimmune lipid disturbances are primarily observed in children who progressed to T1D early, within the first years of life, and such changes can be observed as early as at birth $[194,195]$. The causes of lipid disturbances in, and their relevance to, T1D pathogenesis have remained elusive. This may have changed recently, given results from a study carried out on a mother-child cohort, where McGlinchey et al. found that high prenatal exposure to PFAS decreases the levels of the same lipids in newborn babies as those previously found to be associated with progression to T1D [34]. The same study also reported the association of PFAS exposure with the onset of islet autoimmunity in children. These findings were confirmed in the DIABIMMUNE cohort, a prospective birth cohort [34]. In the same study, McGlinchey et al. show that high HLA-conferred risk of T1D in infants exacerbated the impact of prenatal exposure to PFAS on postnatal T1D-associated lipid levels [34], suggesting a potentially important and specific role of gene-environment interaction in the development of T1D. Within the same investigation, the causal role of PFAS on postnatal lipid profiles, as well as (previously reported $[132,133]$ ) accelerated insulitis, was confirmed in two studies in NOD mice. This study, linking prenatal exposures to PFAS with the postnatal risk of T1D, combined with the aforementioned recent ban on certain PFAS compounds use, may explain the changing trend in the incidence of T1D in certain western countries, thereby also highlighting the need for similar investigations regarding other immune-mediated diseases showing similar incidence trends since the 1950s [178]. The study also exemplifies the MITM approach in exposome research, where chemical exposures are linked to specific adverse health outcomes via intermediate phenotypes such as the metabolome.

\subsection{Allergy and Obstructive Lung Disease}

There is an extensive body of literature on the relationship between environmental exposures and allergic sensitization as well as the causal role in the onset of obstructive lung disease [196-200]. It is not feasible to adequately review this information in the current paper, which is primarily focused on metabolic diseases and diabetes. Instead, we provide a brief summary of the field in relation to the exposome concept $[5,201,202]$. The lungs are a major route of exposure to the external environment. The average minute ventilation is $6 \mathrm{~L}$ per minute under rest and increases as high as 30 $\mathrm{L}$ per minute during exercise. This volume of air is a significant potential exposure source. Exposure to air pollutants has been linked with the inception, development, and exacerbations of allergic and pulmonary diseases (in addition to indoor and outdoor aeroallergens) [201]. In particular, traffic-related air pollutants (TRAPs) including nitrogen dioxide $\left(\mathrm{NO}_{2}\right)$, ozone $\left(\mathrm{O}_{3}\right)$, volatile organic compounds, and particulate matter (PM), as well as environmental tobacco smoke (ETS), have been linked with allergic sensitization and asthma [5,203-205] as has household air pollution [206]. There are numerous reports on the relationship between exposure to TRAP and ETS with the onset of respiratory diseases and interested readers are referred to recent reviews [207]. However, it should be emphasized in the context of lung diseases that the exposome constitutes more than the collection of air pollutants that are recognized triggers for lung injury. Airborne PM contains diverse populations of bacteria, viruses and fungi that affect respiratory health through infections and modulation of the immune system [208]. A consensus document from the American Academy of Allergy, Asthma, and Immunology (AAAAI) and the European Academy of Allergy and Clinical Immunology (EAACI) reported that the exposomic approach is particularly applicable to allergic diseases and asthma because it provides a risk profile instead of single predictors [209]. The power of an exposomics approach becomes clearer in the context 
of mixtures-based exposures-for example, simultaneous allergen and diesel exhaust [210] or allergen and phthalates [211-213].

While air pollutants are a known risk factor for asthma and chronic obstructive pulmonary disease (COPD) [214], their role in allergic diseases in general is not well established [203]. Moreover, the composition of PM has typically not been investigated in this context. PM is composed of a complex mixture of both inorganic (e.g., trace elements) and organic compounds (e.g., PAHs, alkanes), and the composition can be variable, depending on the source. Thus, linking only the amount of PM with specific health outcomes may not give a realistic picture of the possible associations. Currently, there are relatively few clinical cohort studies reported on the relationship between exposome-metabolome allergy. A recent European Human Early-Life Exposome cohort study found no association between any of the broad spectrum of childhood environmental studies and allergy-related health outcomes, while prenatal exposure to mono-4-methyl-7-oxooctyl phthalate was associated with an increased risk of rhinitis, whereas PM absorbance was associated with a decreased risk [215]. Exposure to phthalates has been associated with decreased risk of eczema in some studies [216], but not others [217]. It should be noted here that phthalates have a short half-life and the concentrations will therefore be variable, plausibly explaining the inconsistent findings reported in the literature. The European Food Safety Authority (EFSA) reported that PFAS exposure has showed no or inconsistent associations with asthma and allergies for both prenatal and postnatal exposures as well as in children and adults [218]; however, a recent study with the (National Health and Nutrition Examination Survey) NHANES cohort reported a weak association between serum PFAS levels and asthma prevalence in children [219]. A recent metareview reported that perfluorononanoic acid was associated with eczema, perfluorooctanesulfonic acid with atopic dermatitis and perfluorooctanoic acid with allergic rhinitis, while no significant associations were found for wheeze and asthma [220].

A number of specific compounds have been linked with increased risk of food allergy [221]. For example, the antibacterial agent triclosan has been positively associated with food and aeroallergen sensitization in male children in the NHANES cohort [222]; however, neither a Norwegian study nor a study from the USA observed an association between triclosan exposure and food allergen sensitization $[223,224]$. A few studies have examined the impact of phthalate exposure and have found that it is associated with an increased risk for food sensitization in children [225,226]. Given the increasing incidence of food allergies $[227,228]$, this will be an important area of future study.

Given that obstructive lung disease and allergy have low genetic determination [229], there is a vital role for application of the exposome concept to increase our understanding of disease etiology. It is expected that exposome investigations will provide insight into the role that complex environmental mixtures exert in the onset and pathophysiology of allergic sensitization and pulmonary disease. However, as with other exposome-based studies, it will be important to ensure proper study design and to examine, in particular, the role of pre-natal exposures.

\section{Conclusions}

The applications of metabolomics to exposome research, aiming to link external exposures with adverse outcome pathways and health outcomes, are an increasingly active area of research [67]. Although already being addressed in current research, two main challenges in exposome research still remain:

1. Analytical coverage. Given the enormous complexity of the chemical exposome, and the vast number of chemicals to consider, at concentration ranges covering several orders of magnitude, analysis of these chemicals alongside the metabolome is challenging at the very least. One limitation, particularly in human cohort studies, is also the amount (physical volume) of sample available for the analysis, which limits the number of different analytical methods that can be applied to the same sample. This favors analytical methods with broad analytical coverage, yet this often leads to inevitable tradeoffs in terms of accuracy of quantification as well as sensitivity. 
2. Data integration and establishing causal relationships between exposures and adverse health outcomes. As also shown in this review, a large number of studies have established associations between specific chemical exposures and metabolic outcomes (i.e., clinical metabolic markers or metabolomics) or specific adverse health outcomes. However, in most cases, the question remains if these are true causal relationships or associations confounded by other factors such as diet. This challenge is likely to become even greater with increasing analytical coverage of the chemical exposome and metabolome, and with the inclusion of other data such as from the gut microbiome. Establishing causality is crucial if one is to consider the safety of specific chemicals or specific prevention measures. The elimination of spurious associations (e.g., by a rejection-rate-filtered partial correlation network approach), the identification of key toxic drivers (e.g., by regression of selected chemicals with selected outcomes of interest), and follow-up with targeted exposure studies in relevant experimental models [34], are likely to be key research strategies suitable for tackling the challenge of data integration and proving causality in exposome research.

Given the active research in the exposome field, it is likely that the future will bring many innovative solutions to address the above challenges. Such advances will have the potential to open new areas of investigation related to the study of the impact of real-world chemical exposures on human health and for more accurate chemical safety assessment, as well as challenge our current views about the origin and pathogenesis of many common diseases.

Funding: The current work was supported by the Swedish Research Council (No. 2016-05176 to TH, No. 2016-02798 to C.E.W.), Formas (No. 2019-00869 to T.H. and M.O.), Academy of Finland (No. 333981 to M.O.), and Swedish Heart Lung Foundation (HLF 20170734 and HLF 20180290 to C.E.W.).

Conflicts of Interest: The authors declare no conflict of interest.

$\begin{array}{ll}\text { Abbreviations } & \\ \text { 12-oxo-LCA } & \text { 12-Oxolithocholic acid } \\ \text { 7-oxo-DCA } & \text { 7-Oxodeoxycholic acid } \\ \text { 7-oxo-HCA } & \text { 7-Oxohyocholic acid } \\ \text { ANN } & \text { Artificial neural networks } \\ \text { AT } & \text { Adipose tissue } \\ \text { BA } & \text { Bile acids } \\ \text { BAAT } & \text { Bile acid CoA: amino acid N-acetyltransferase } \\ \text { BACS } & \text { Bile acid-coenzyme A synthase } \\ \text { BADGE } & \text { Bisphenol A diglycidyl ether } \\ \text { BPA } & \text { Bisphenol A } \\ \text { BSE } & \text { Bile salt export pump } \\ \text { CA } & \text { Cholic acid } \\ \text { CDCA } & \text { Chenodeoxycholic acid } \\ \text { CE } & \text { Cholesteryl ester } \\ \text { Cer } & \text { Ceramide } \\ \text { CYP7A1 } & \text { Cytochrome P450 family 7 subfamily A member 1 } \\ \text { DCA } & \text { Deoxycholic acid } \\ \text { DDA } & \text { Data-dependent acquisition } \\ \text { DDE } & \text { Dichlorodiphenyldichloroethylene } \\ \text { DES } & \text { Diethylstilbestrol } \\ \text { DG } & \text { Diradylglycerol } \\ \text { DHCA } & 3 \alpha, 7 \alpha \text {-Dihydroxycholestanoic acid } \\ \text { DIA } & \text { Data independent acquisition } \\ \text { EFSA } & \text { European Food Safety Authority } \\ \text { FT-ICR } & \text { Fourier transform ion cyclotron resonance } \\ \text { FXR } & \text { Farnesyl-X-receptor } \\ \text { FXR } & \text { Gas chromatography } \\ \text { GC } & \end{array}$




\begin{tabular}{|c|c|}
\hline GCA & Glycocholic acid \\
\hline GCDCA & Glycochenodeoxycholic acid \\
\hline GDCA & Glycodeoxycholic acid \\
\hline GDHCA & Glycodehydrocholic acid \\
\hline GHCA & Glycohyocholic acid \\
\hline GHDCA & Glycohyodeoxycholic acid \\
\hline GLCA & Glycolithocholic acid \\
\hline GUDCA & Glycoursodeoxycholic acid \\
\hline HCA & Hyocholic acid \\
\hline $\mathrm{HCB}$ & Hexachlorobenzene \\
\hline HDCA & Hyodeoxycholic acid \\
\hline HLA & Human leukocyte antigen \\
\hline HNF4a & Hepatocyte nuclear factor 4 alpha \\
\hline HRMS & High-resolution mass spectrometry \\
\hline IT-TOFMS & Ion trap-time-of-flight mass spectrometry \\
\hline LCA & Lithocholic acid \\
\hline LPC & Lysophosphatidylcholine \\
\hline L-PFOS & Linear-perfluorooctane sulfonate \\
\hline MITM & Meet-in-the-middle \\
\hline $\mathrm{MnBP}$ & Mono-n-butyl phthalate \\
\hline NAFLD & Non-alcoholic fatty liver disease \\
\hline $\mathrm{NO} 2$ & Nitrogen dioxide \\
\hline NTCP & Sodium taurocholate co-transporting polypeptide \\
\hline $\mathrm{O} 3$ & Ozone \\
\hline $\mathrm{OST} \alpha / \beta$ & Organic solute transporter $\alpha / \beta$ \\
\hline PAH & Polyaromatic hydrocarbons \\
\hline $\mathrm{PAH}$ & Polycyclic aromatic hydrocarbons \\
\hline PBDE & Polybrominated diphenyl ether \\
\hline PC & Phosphatidylcholine \\
\hline PC ethers & Phosphatidylcholine ether \\
\hline PCB & Polychlorinated biphenyls \\
\hline PE & Phospatidylethanolamine \\
\hline PFAS & Per- and polyfluoroalkyl substances \\
\hline PFBA & Perfluorobutanoic acid \\
\hline PFBS & Perfluorobutane sulfonate \\
\hline PFDA & Perfluorodecanoic acid \\
\hline PFDS & Perfluorodecane sulfonate \\
\hline PFECHS & Potassium perfluoro-4-ethylcyclohexanesulfonate \\
\hline PFHpA & Perfluoroheptanoic acid \\
\hline PFHpS & Perfluoroheptane sulfonate \\
\hline PFHxS & Perfluorohexane sulfonate \\
\hline PFNA & Perfluorononanoic acid \\
\hline PFNS & Perfluorononane sulfonate \\
\hline PFOA & Perfluorooctanoic acid \\
\hline PFOSA & Perfluorooctane sulfonamide \\
\hline PFPeA & Perfluoropentanoic acid \\
\hline PFPeS & Perfluoro pentane sulfonate \\
\hline PFTDA & Perfluorotetradecanoic acid \\
\hline PFTrDA & Perfluorotridecanoic acid \\
\hline PFUnDA & Perfluoroundecanoic acid \\
\hline PI & Phosphatidylinositol \\
\hline PM & Particulate matter \\
\hline POP & Persistent organic pollutants \\
\hline ROS & Reactive oxygen species \\
\hline SM & Sphingomyelin \\
\hline T1D & Type 1 diabetes \\
\hline
\end{tabular}




$\begin{array}{ll}\text { T2D } & \text { Type } 2 \text { diabetes } \\ \text { TBT } & \text { Tributyltin } \\ \text { TCA } & \text { Taurocholic acid } \\ \text { TCA } & \text { Tricarboxylic acid cycle } \\ \text { TCDCA } & \text { Taurochenodeoxycholic acid } \\ \text { TDCA } & \text { Taurodeoxycholic acid } \\ \text { TDHCA } & \text { Taurohyodeoxycholic acid } \\ \text { TG } & \text { Triradylglycerol } \\ \text { THCA } & \text { Taurodeoxycholic acid } \\ \text { THDCA } & \text { Taurohyodeoxycholic acid } \\ \text { TLCA } & \text { Taurolithocholic acid } \\ \text { TRAP } & \text { Traffic-related air pollutants } \\ \text { TUDCA } & \text { Tauroursodeoxycholic acid } \\ \text { T } \alpha \beta \text { MCA } & \alpha, \beta \text {-Tauromuricholic acid } \\ \text { T } \omega \text { MCA } & \omega \text {-Tauromuricholic acid } \\ \text { UDCA } & \text { Ursodeoxycholic acid } \\ \text { UGT } & \text { UDP-glucosyltransferases } \\ \text { UHPLC } & \text { Ultra-performance liquid chromatography } \\ \beta-H C H & \beta \text {-hexachlorocyclohexane } \\ \beta M C A & \beta \text {-Muricholic acid } \\ \omega \alpha M C A & \omega \text {-Tauromuricholic acid }\end{array}$

\section{References}

1. Rappaport, S.M. Implications of the exposome for exposure science. J. Expo. Sci. Environ. Epidemiol. 2011, 21, 5-9. [CrossRef] [PubMed]

2. Rattray, N.J.W.; Deziel, N.C.; Wallach, J.D.; Khan, S.A.; Vasiliou, V.; Ioannidis, J.P.A.; Johnson, C.H. Beyond genomics: Understanding exposotypes through metabolomics. Hum. Genom. 2018, 12, 4. [CrossRef] [PubMed]

3. Wild, C.P. Complementing the Genome with an "Exposome": The Outstanding Challenge of Environmental Exposure Measurement in Molecular Epidemiology. Cancer Epidemiol. Biomark. Prev. 2005, 14, 1847-1850. [CrossRef] [PubMed]

4. Rappaport, S.M.; Barupal, D.K.; Wishart, D.; Vineis, P.; Scalbert, A. The blood exposome and its role in discovering causes of disease. Environ. Health Perspect 2014, 122, 769-774. [CrossRef] [PubMed]

5. Wheelock, C.E.; Rappaport, S.M. The role of gene-environment interactions in lung disease: The urgent need for the exposome. Eur. Respir. J. 2020, 55. [CrossRef] [PubMed]

6. Vermeulen, R.; Schymanski, E.L.; Barabasi, A.L.; Miller, G.W. The exposome and health: Where chemistry meets biology. Science 2020, 367, 392-396. [CrossRef]

7. Miller, G.W.; Jones, D.P. The nature of nurture: Refining the definition of the exposome. Toxicol. Sci. 2014, 137, 1-2. [CrossRef]

8. Zhang, P.; Arora, M.; Chaleckis, R.; Isobe, T.; Jain, M.; Meister, I.; Melen, E.; Perzanowski, M.; Torta, F.; Wenk, M.R.; et al. Tackling the Complexity of the Exposome: Considerations from the Gunma University Initiative for Advanced Research (GIAR) Exposome Symposium. Metabolites 2019, 9, 106. [CrossRef]

9. European Chemicals Agency. Guidance for the Identification and Naming of the Substances under REACH and CLP; European Chemicals Agency: Helsinki, Finland, 2017. [CrossRef]

10. Pollock, T.; Weaver, R.E.; Ghasemi, R.; deCatanzaro, D. A mixture of five endocrine-disrupting chemicals modulates concentrations of bisphenol A and estradiol in mice. Chemosphere 2018, 193, 321-328. [CrossRef]

11. Appenzeller, B.M.R.; Chadeau-Hyam, M.; Aguilar, L. Skin exposome science in practice: Current evidence on hair biomonitoring and future perspectives. J. Eur. Acad. Derm. Venereol. 2020, 34 (Suppl. 4), 26-30. [CrossRef]

12. Leung, M.H.Y.; Tong, X.; Bastien, P.; Guinot, F.; Tenenhaus, A.; Appenzeller, B.M.R.; Betts, R.J.; Mezzache, S.; $\mathrm{Li}$, J.; Bourokba, N.; et al. Changes of the human skin microbiota upon chronic exposure to polycyclic aromatic hydrocarbon pollutants. Microbiome 2020, 8, 100. [CrossRef] [PubMed] 
13. Pumarega, J.; Gasull, M.; Lee, D.H.; Lopez, T.; Porta, M. Number of Persistent Organic Pollutants Detected at High Concentrations in Blood Samples of the United States Population. PLoS ONE 2016, 11, e0160432. [CrossRef] [PubMed]

14. Rappaport, S.M. Redefining environmental exposure for disease etiology. Npj. Syst. Biol. Appl. 2018, 4, 30. [CrossRef] [PubMed]

15. Andra, S.S.; Austin, C.; Patel, D.; Dolios, G.; Awawda, M.; Arora, M. Trends in the application of high-resolution mass spectrometry for human biomonitoring: An analytical primer to studying the environmental chemical space of the human exposome. Environ. Int. 2017, 100, 32-61. [CrossRef]

16. Athersuch, T. Metabolome analyses in exposome studies: Profiling methods for a vast chemical space. Arch. Biochem. Biophys. 2016, 589, 177-186. [CrossRef]

17. Athersuch, T.J.; Keun, H.C. Metabolic profiling in human exposome studies. Mutagenesis 2015, 30, 755-762. [CrossRef]

18. Ellis, J.K.; Athersuch, T.J.; Thomas, L.D.; Teichert, F.; Pérez-Trujillo, M.; Svendsen, C.; Spurgeon, D.J.; Singh, R.; Järup, L.; Bundy, J.G.; et al. Metabolic profiling detects early effects of environmental and lifestyle exposure to cadmium in a human population. BMC Med. 2012, 10, 61. [CrossRef]

19. Lai, Y.; Xue, J.; Liu, C.-W.; Gao, B.; Chi, L.; Tu, P.; Lu, K.; Ru, H. Serum Metabolomics Identifies Altered Bioenergetics, Signaling Cascades in Parallel with Exposome Markers in Crohn's Disease. Molecules 2019, 24, 449. [CrossRef]

20. Li, S.; Cirillo, P.; Hu, X.; Tran, V.; Krigbaum, N.; Yu, S.; Jones, D.P.; Cohn, B. Understanding mixed environmental exposures using metabolomics via a hierarchical community network model in a cohort of California women in 1960's. Reprod. Toxicol. 2019. [CrossRef]

21. Maitre, L.; Robinson, O.; Martinez, D.; Toledano, M.B.; Ibarluzea, J.; Marina, L.S.; Sunyer, J.; Villanueva, C.M.; Keun, H.C.; Vrijheid, M.; et al. Urine Metabolic Signatures of Multiple Environmental Pollutants in Pregnant Women: An Exposome Approach. Environ. Sci. Technol. 2018, 52, 13469-13480. [CrossRef]

22. Mapesa, J.O.; Maxwell, A.L.; Ryan, E.P. An Exposome Perspective on Environmental Enteric Dysfunction. Environ. Health Perspect 2016, 124, 1121-1126. [CrossRef] [PubMed]

23. Lind, L.; Zethelius, B.; Salihovic, S.; van Bavel, B.; Lind, P.M.J.D. Circulating levels of perfluoroalkyl substances and prevalent diabetes in the elderly. Diabetologia 2014, 57, 473-479. [CrossRef] [PubMed]

24. Salihovic, S.; Fall, T.; Ganna, A.; Broeckling, C.D.; Prenni, J.E.; Hyötyläinen, T.; Kärrman, A.; Lind, P.M.; Ingelsson, E.; Lind, L. Identification of metabolic profiles associated with human exposure to perfluoroalkyl substances. J. Expo. Sci. Environ. Epidemiol. 2018. [CrossRef] [PubMed]

25. Salihovic, S.; Ganna, A.; Fall, T.; Broeckling, C.D.; Prenni, J.E.; van Bavel, B.; Lind, P.M.; Ingelsson, E.; Lind, L. The metabolic fingerprint of p, $\mathrm{p}^{\prime}$-DDE and HCB exposure in humans. Environ. Int. 2016, 88, 60-66. [CrossRef]

26. Sun, Q.; Zong, G.; Valvi, D.; Nielsen, F.; Coull, B.; Grandjean, P. Plasma Concentrations of Perfluoroalkyl Substances and Risk of Type 2 Diabetes: A Prospective Investigation among U.S. Women. Environ. Health Perspect. 2018, 126, 037001. [CrossRef]

27. Dzierlenga, M.W.; Yoon, M.; Wania, F.; Ward, P.L.; Armitage, J.M.; Wood, S.A.; Clewell, H.J.; Longnecker, M.P. Quantitative bias analysis of the association of type 2 diabetes mellitus with 2,2' $4,4^{\prime}, 5,5^{\prime}$-hexachlorobiphenyl (PCB-153). Environ. Int. 2019, 125, 291-299. [CrossRef]

28. Lee, D.-H.; Porta, M.; Jacobs, D.R., Jr.; Vandenberg, L.N. Chlorinated Persistent Organic Pollutants, Obesity, and Type 2 Diabetes. Endocr. Rev. 2014, 35, 557-601. [CrossRef]

29. Tornevi, A.; Sommar, J.; Rantakokko, P.; Åkesson, A.; Donat-Vargas, C.; Kiviranta, H.; Rolandsson, O.; Rylander, L.; Wennberg, M.; Bergdahl, I.A. Chlorinated persistent organic pollutants and type 2 diabetes-A population-based study with pre- and post- diagnostic plasma samples. Environ. Res. 2019, 174, 35-45. [CrossRef]

30. Beggs, K.M.; McGreal, S.R.; McCarthy, A.; Gunewardena, S.; Lampe, J.N.; Lau, C.; Apte, U. The role of hepatocyte nuclear factor 4-alpha in perfluorooctanoic acid- and perfluorooctanesulfonic acid-induced hepatocellular dysfunction. Toxicol. Appl. Pharmacol. 2016, 304, 18-29. [CrossRef]

31. Sarigiannis, D.A. Assessing the impact of hazardous waste on children's health: The exposome paradigm. Environ. Res 2017, 158, 531-541. [CrossRef] 
32. Kawamoto, T.; Nitta, H.; Murata, K.; Toda, E.; Tsukamoto, N.; Hasegawa, M.; Yamagata, Z.; Kayama, F.; Kishi, R.; Ohya, Y.; et al. Rationale and study design of the Japan environment and children's study (JECS). BMC Public Health 2014, 14, 25. [CrossRef] [PubMed]

33. Sinisalu, L.; Sen, P.; Salihovic, S.; Virtanen, S.M.; Hyoty, H.; Ilonen, J.; Toppari, J.; Veijola, R.; Oresic, M.; Knip, M.; et al. Early-life exposure to perfluorinated alkyl substances modulates lipid metabolism in progression to celiac disease. Environ. Res. 2020, 188, 109864. [CrossRef] [PubMed]

34. McGlinchey, A.; Sinioja, T.; Lamichhane, S.; Sen, P.; Bodin, J.; Siljander, H.; Dickens, A.M.; Geng, D.; Carlsson, C.; Duberg, D.; et al. Prenatal exposure to perfluoroalkyl substances modulates neonatal serum phospholipids, increasing risk of type 1 diabetes. Environ. Int. 2020, 143, 105935. [CrossRef] [PubMed]

35. Ziegler, A.G.; Rewers, M.; Simell, O.; Simell, T.; Lempainen, J.; Steck, A.; Winkler, C.; Ilonen, J.; Veijola, R.; Knip, M.; et al. Seroconversion to multiple islet autoantibodies and risk of progression to diabetes in children. JAMA 2013, 309, 2473-2479. [CrossRef]

36. Warth, B.; Spangler, S.; Fang, M.; Johnson, C.H.; Forsberg, E.M.; Granados, A.; Martin, R.L.; Domingo-Almenara, X.; Huan, T.; Rinehart, D.; et al. Exposome-Scale Investigations Guided by Global Metabolomics, Pathway Analysis, and Cognitive Computing. Anal. Chem. 2017, 89, 11505-11513. [CrossRef]

37. Escher, B.I.; Stapleton, H.M.; Schymanski, E.L. Tracking complex mixtures of chemicals in our changing environment. Science 2020, 367, 388-392. [CrossRef]

38. Chadeau-Hyam, M.; Athersuch, T.J.; Keun, H.C.; De Iorio, M.; Ebbels, T.M.; Jenab, M.; Sacerdote, C.; Bruce, S.J.; Holmes, E.; Vineis, P. Meeting-in-the-middle using metabolic profiling-A strategy for the identification of intermediate biomarkers in cohort studies. Biomarkers 2011, 16, 83-88. [CrossRef]

39. Hartonen, M.; Mattila, I.; Ruskeepaa, A.L.; Oresic, M.; Hyotylainen, T. Characterization of cerebrospinal fluid by comprehensive two-dimensional gas chromatography coupled to time-of-flight mass spectrometry. J. Chromatogr. A 2013, 1293, 142-149. [CrossRef]

40. Hyotylainen, T.; Oresic, M. Analytical Lipidomics in Metabolic and Clinical Research. Trends Endocrinol. Metab. 2015, 26, 671-673. [CrossRef]

41. Heli Nygren, T.S.-L.; Sandra, C.; Tuulia, H.; Matej, O. LC/MS-based lipidomics for studies of body fluids and tissues. Methods Mol. Biol. 2011, 708, 11.

42. Hyotylainen, T.; Oresic, M. Optimizing the lipidomics workflow for clinical studies-Practical considerations. Anal. Bioanal. Chem. 2015, 407, 4973-4993. [CrossRef] [PubMed]

43. Klavus, A.; Kokla, M.; Noerman, S.; Koistinen, V.M.; Tuomainen, M.; Zarei, I.; Meuronen, T.; Hakkinen, M.R.; Rummukainen, S.; Farizah Babu, A.; et al. "Notame": Workflow for Non-Targeted LC-MS Metabolic Profiling. Metabolites 2020, 10, 135. [CrossRef] [PubMed]

44. Wang, X.; Yu, N.; Yang, J.; Jin, L.; Guo, H.; Shi, W.; Zhang, X.; Yang, L.; Yu, H.; Wei, S. Suspect and non-target screening of pesticides and pharmaceuticals transformation products in wastewater using QTOF-MS. Environ. Int. 2020, 137, 105599. [CrossRef] [PubMed]

45. Li, Y.; Yu, N.; Du, L.; Shi, W.; Yu, H.; Song, M.; Wei, S. Transplacental Transfer of Per- and Polyfluoroalkyl Substances Identified in Paired Maternal and Cord Sera Using Suspect and Nontarget Screening. Environ. Sci. Technol. 2020, 54, 3407-3416. [CrossRef]

46. Wang, A.; Gerona, R.R.; Schwartz, J.M.; Lin, T.; Sirota, M.; Morello-Frosch, R.; Woodruff, T.J. A Suspect Screening Method for Characterizing Multiple Chemical Exposures among a Demographically Diverse Population of Pregnant Women in San Francisco. Environ. Health Perspect. 2018, 126, 077009. [CrossRef]

47. Hollender, J.; Schymanski, E.L.; Singer, H.P.; Ferguson, P.L. Nontarget Screening with High Resolution Mass Spectrometry in the Environment: Ready to Go? Environ. Sci. Technol. 2017, 51, 11505-11512. [CrossRef]

48. Gerona, R.R.; Schwartz, J.M.; Pan, J.; Friesen, M.M.; Lin, T.; Woodruff, T.J. Suspect screening of maternal serum to identify new environmental chemical biomonitoring targets using liquid chromatography-quadrupole time-of-flight mass spectrometry. J. Expo. Sci. Environ. Epidemiol. 2018, 28, 101-108. [CrossRef]

49. Ma, Y.; Kind, T.; Yang, D.; Leon, C.; Fiehn, O. MS2Analyzer: A software for small molecule substructure annotations from accurate tandem mass spectra. Anal. Chem. 2014, 86, 10724-10731. [CrossRef]

50. Aguilar-Mogas, A.; Sales-Pardo, M.; Navarro, M.; Guimera, R.; Yanes, O. iMet: A Network-Based Computational Tool to Assist in the Annotation of Metabolites from Tandem Mass Spectra. Anal. Chem. 2017, 89, 3474-3482. [CrossRef] 
51. Treutler, H.; Tsugawa, H.; Porzel, A.; Gorzolka, K.; Tissier, A.; Neumann, S.; Balcke, G.U. Discovering Regulated Metabolite Families in Untargeted Metabolomics Studies. Anal. Chem. 2016, 88, 8082-8090. [CrossRef]

52. Tsugawa, H.; Kind, T.; Nakabayashi, R.; Yukihira, D.; Tanaka, W.; Cajka, T.; Saito, K.; Fiehn, O.; Arita, M. Hydrogen Rearrangement Rules: Computational MS/MS Fragmentation and Structure Elucidation Using MS-FINDER Software. Anal. Chem. 2016, 88, 7946-7958. [CrossRef] [PubMed]

53. Cheng, T.F.; Zhang, Y.H.; Ye, J.; Jin, H.Z.; Zhang, W.D. Investigation of the chemical compounds in Pheretima aspergillum (E. Perrier) using a combination of mass spectral molecular networking and unsupervised substructure annotation topic modeling together with in silico fragmentation prediction. J. Pharm. Biomed. Anal. 2020, 184, 113197. [CrossRef] [PubMed]

54. Rogers, S.; Ong, C.W.; Wandy, J.; Ernst, M.; Ridder, L.; van der Hooft, J.J.J. Deciphering complex metabolite mixtures by unsupervised and supervised substructure discovery and semi-automated annotation from MS/MS spectra. Faraday Discuss. 2019, 218, 284-302. [CrossRef] [PubMed]

55. Qiu, F.; Lei, Z.; Sumner, L.W. MetExpert: An expert system to enhance gas chromatographymass spectrometry-based metabolite identifications. Anal. Chim. Acta 2018, 1037, 316-326. [CrossRef] [PubMed]

56. Ljoncheva, M.; Stepišnik, T.; Džeroski, S.; Kosjek, T. Cheminformatics in MS-based environmental exposomics: Current achievements and future directions. Trends Environ. Anal. Chem. 2020, 28, e00099. [CrossRef]

57. McEachran, A.D.; Mansouri, K.; Grulke, C.; Schymanski, E.L.; Ruttkies, C.; Williams, A.J. "MS-Ready" structures for non-targeted high-resolution mass spectrometry screening studies. J. Cheminform. 2018, 10, 45. [CrossRef]

58. Koelmel, J.P.; Kroeger, N.M.; Ulmer, C.Z.; Bowden, J.A.; Patterson, R.E.; Cochran, J.A.; Beecher, C.W.W.; Garrett, T.J.; Yost, R.A. LipidMatch: An automated workflow for rule-based lipid identification using untargeted high-resolution tandem mass spectrometry data. BMC Bioinform. 2017, 18, 331. [CrossRef]

59. Schnelle-Kreis, J.; Welthagen, W.; Sklorz, M.; Zimmermann, R. Application of direct thermal desorption gas chromatography and comprehensive two-dimensional gas chromatography coupled to time of flight mass spectrometry for analysis of organic compounds in ambient aerosol particles. J. Sep. Sci. 2005, 28, 1648-1657. [CrossRef]

60. Hummel, J.; Strehmel, N.; Selbig, J.; Walther, D.; Kopka, J.J.M. Decision tree supported substructure prediction of metabolites from GC-MS profiles. Metabolomics 2010, 6, 322-333. [CrossRef]

61. Agier, L.; Portengen, L.; Chadeau-Hyam, M.; Basagana, X.; Giorgis-Allemand, L.; Siroux, V.; Robinson, O.; Vlaanderen, J.; Gonzalez, J.R.; Nieuwenhuijsen, M.J.; et al. A Systematic Comparison of Linear Regression-Based Statistical Methods to Assess Exposome-Health Associations. Environ. Health Perspect. 2016, 124, 1848-1856. [CrossRef]

62. Bobb, J.F.; Claus Henn, B.; Valeri, L.; Coull, B.A. Statistical software for analyzing the health effects of multiple concurrent exposures via Bayesian kernel machine regression. Environ. Health 2018, 17, 67. [CrossRef] [PubMed]

63. Scrucca, L.; Fop, M.; Murphy, T.B.; Raftery, A.E. mclust 5: Clustering, Classification and Density Estimation Using Gaussian Finite Mixture Models. R J. 2016, 8, 289-317. [CrossRef] [PubMed]

64. Castelo, R.; Roverato, A. Reverse engineering molecular regulatory networks from microarray data with qp-graphs. J. Comp. Biol. 2009, 16, 213-227. [CrossRef]

65. Sen, P.; Lamichhane, S.; Mathema, V.B.; McGlinchey, A.; Dickens, A.M.; Khoomrung, S.; Oresic, M. Deep learning meets metabolomics: A methodological perspective. Brief. Bioinform. 2020. [CrossRef] [PubMed]

66. Mendez, K.M.; Reinke, S.N.; Broadhurst, D.I. A comparative evaluation of the generalised predictive ability of eight machine learning algorithms across ten clinical metabolomics data sets for binary classification. Metabolomics 2019, 15, 150. [CrossRef] [PubMed]

67. Walker, D.I.; Valvi, D.; Rothman, N.; Lan, Q.; Miller, G.W.; Jones, D.P. The metabolome: A key measure for exposome research in epidemiology. Curr. Epidemiol. Rep. 2019, 6, 93-103. [CrossRef]

68. Coelho, M.; Oliveira, T.; Fernandes, R. Biochemistry of adipose tissue: An endocrine organ. Arch. Med. Sci. 2013, 9, 191-200. [CrossRef]

69. La Merrill, M.; Emond, C.; Kim, M.J.; Antignac, J.P.; Le Bizec, B.; Clement, K.; Birnbaum, L.S.; Barouki, R. Toxicological function of adipose tissue: Focus on persistent organic pollutants. Environ. Health Perspect. 2013, 121, 162-169. [CrossRef] 
70. Jackson, E.; Shoemaker, R.; Larian, N.; Cassis, L. Adipose Tissue as a Site of Toxin Accumulation. Compr. Physiol. 2017, 7, 1085-1135. [CrossRef]

71. Heindel, J.J.; Blumberg, B.; Cave, M.; Machtinger, R.; Mantovani, A.; Mendez, M.A.; Nadal, A.; Palanza, P.; Panzica, G.; Sargis, R.; et al. Metabolism disrupting chemicals and metabolic disorders. Reprod. Toxicol. 2017, 68, 3-33. [CrossRef]

72. Angle, B.M.; Do, R.P.; Ponzi, D.; Stahlhut, R.W.; Drury, B.E.; Nagel, S.C.; Welshons, W.V.; Besch-Williford, C.L.; Palanza, P.; Parmigiani, S.; et al. Metabolic disruption in male mice due to fetal exposure to low but not high doses of bisphenol A (BPA): Evidence for effects on body weight, food intake, adipocytes, leptin, adiponectin, insulin and glucose regulation. Reprod. Toxicol. 2013, 42, 256-268. [CrossRef]

73. Hao, C.; Cheng, X.; Xia, H.; Ma, X. The endocrine disruptor mono-(2-ethylhexyl) phthalate promotes adipocyte differentiation and induces obesity in mice. Biosci. Rep. 2012, 32, 619-629. [CrossRef] [PubMed]

74. La Merrill, M.; Karey, E.; Moshier, E.; Lindtner, C.; La Frano, M.R.; Newman, J.W.; Buettner, C. Perinatal exposure of mice to the pesticide DDT impairs energy expenditure and metabolism in adult female offspring. PLoS ONE 2014, 9, e103337. [CrossRef] [PubMed]

75. Mentor, A.; Brunstrom, B.; Mattsson, A.; Jonsson, M. Developmental exposure to a human relevant mixture of endocrine disruptors alters metabolism and adipogenesis in zebrafish (Danio rerio). Chemosphere 2020, 238, 124584. [CrossRef]

76. Valvi, D.; Casas, M.; Mendez, M.A.; Ballesteros, G.A.; Luque, N.; Rubio, S.; Sunyer, J.; Vrijheid, M. Prenatal Bisphenol A Urine Concentrations and Early Rapid Growth and Overweight Risk in the Offspring. Epidemiology 2013, 24, 791-799. [CrossRef] [PubMed]

77. Braun, J.M.; Lanphear, B.P.; Calafat, A.M.; Deria, S.; Khoury, J.; Howe, C.J.; Venners, S.A. Early-Life Bisphenol A Exposure and Child Body Mass Index: A Prospective Cohort Study. Environ. Health Perspect. 2014, 122, 1239-1245. [CrossRef]

78. Hoepner, L.A.; Whyatt, R.M.; Widen, E.M.; Hassoun, A.; Oberfield, S.E.; Mueller, N.T.; Diaz, D.; Calafat, A.M.; Perera, F.P.; Rundle, A.G. Bisphenol A and Adiposity in an Inner-City Birth Cohort. Environ. Health Perspect. 2016, 124, 1644-1650. [CrossRef]

79. Lee, Y.M.; Hong, Y.-C.; Ha, M.; Kim, Y.; Park, H.; Kim, H.S.; Ha, E.-H. Prenatal Bisphenol-A exposure affects fetal length growth by maternal glutathione transferase polymorphisms, and neonatal exposure affects child volume growth by sex: From multiregional prospective birth cohort MOCEH study. Sci. Total Environ. 2018, 612, 1433-1441. [CrossRef]

80. Valvi, D.; Mendez, M.A.; Garcia-Esteban, R.; Ballester, F.; Ibarluzea, J.; Goni, F.; Grimalt, J.O.; Llop, S.; Marina, L.S.; Vizcaino, E.; et al. Prenatal exposure to persistent organic pollutants and rapid weight gain and overweight in infancy. Obesity (Silver Spring) 2014, 22, 488-496. [CrossRef]

81. Machala, M.; Slavik, J.; Pencikova, K.; Neca, J.; Simeckova, P.; Kulich, P.; Vondracek, J. Polychlorinated biphenyls as modulators of sphingolipid and prostaglandin metabolism, intercellular communication and cell adhesion. Toxicol. Lett. 2017, 280, S27. [CrossRef]

82. Wang, X.; Xu, Y.; Song, X.; Jia, Q.; Zhang, X.; Qian, Y.; Qiu, J. Analysis of glycerophospholipid metabolism after exposure to PCB153 in PC12 cells through targeted lipidomics by UHPLC-MS/MS. Ecotoxicol. Environ. Saf. 2019, 169, 120-127. [CrossRef] [PubMed]

83. Carrizo, D.; Chevallier, O.P.; Woodside, J.V.; Brennan, S.F.; Cantwell, M.M.; Cuskelly, G.; Elliott, C.T. Untargeted metabolomic analysis of human serum samples associated with exposure levels of Persistent organic pollutants indicate important perturbations in Sphingolipids and Glycerophospholipids levels. Chemosphere 2017, 168, 731-738. [CrossRef] [PubMed]

84. Geng, N.; Zhang, H.; Zhang, B.; Wu, P.; Wang, F.; Yu, Z.; Chen, J. Effects of Short-Chain Chlorinated Paraffins Exposure on the Viability and Metabolism of Human Hepatoma HepG2 Cells. Environ. Sci. Technol. 2015, 49, 3076-3083. [CrossRef] [PubMed]

85. Gao, Y.; Lu, Y.; Huang, S.; Gao, L.; Liang, X.; Wu, Y.; Wang, J.; Huang, Q.; Tang, L.; Wang, G.; et al. Identifying Early Urinary Metabolic Changes with Long-Term Environmental Exposure to Cadmium by Mass-Spectrometry-Based Metabolomics. Environ. Sci. Technol. 2014, 48, 6409-6418. [CrossRef] [PubMed]

86. Zhang, J.; Shen, H.; Xu, W.; Xia, Y.; Barr, D.B.; Mu, X.; Wang, X.; Liu, L.; Huang, Q.; Tian, M. Urinary Metabolomics Revealed Arsenic Internal Dose-Related Metabolic Alterations: A Proof-of-Concept Study in a Chinese Male Cohort. Environ. Sci. Technol. 2014, 48, 12265-12274. [CrossRef] 
87. Dudka, I.; Kossowska, B.; Senhadri, H.; Latajka, R.; Hajek, J.; Andrzejak, R.; Antonowicz-Juchniewicz, J.; Gancarz, R. Metabonomic analysis of serum of workers occupationally exposed to arsenic, cadmium and lead for biomarker research: A preliminary study. Environ. Int. 2014, 68, 71-81. [CrossRef]

88. Wang, Z.; Zheng, Y.; Zhao, B.; Zhang, Y.; Liu, Z.; Xu, J.; Chen, Y.; Yang, Z.; Wang, F.; Wang, H.; et al. Human Metabolic Responses to Chronic Environmental Polycyclic Aromatic Hydrocarbon Exposure by a Metabolomic Approach. J. Proteome Res. 2015, 14, 2583-2593. [CrossRef]

89. Fader, K.A.; Nault, R.; Ammendolia, D.A.; Harkema, J.R.; Williams, K.J.; Crawford, R.B.; Kaminski, N.E.; Potter, D.; Sharratt, B.; Zacharewski, T.R. 2,3,7,8-Tetrachlorodibenzo-p-Dioxin Alters Lipid Metabolism and Depletes Immune Cell Populations in the Jejunum of C57BL/6 Mice. Toxicol. Sci. 2015, 148, 567-580. [CrossRef]

90. Hennig, B.; Reiterer, G.; Toborek, M.; Matveev, S.V.; Daugherty, A.; Smart, E.; Robertson, L.W. Dietary fat interacts with PCBs to induce changes in lipid metabolism in mice deficient in low-density lipoprotein receptor. Environ. Health Perspect. 2005, 113, 83-87. [CrossRef]

91. Luo, Y.S.; Furuya, S.; Soldatov, V.Y.; Kosyk, O.; Yoo, H.S.; Fukushima, H.; Lewis, L.; Iwata, Y.; Rusyn, I. Metabolism and Toxicity of Trichloroethylene and Tetrachloroethylene in Cytochrome P450 2E1 Knockout and Humanized Transgenic Mice. Toxicol. Sci. 2018, 164, 489-500. [CrossRef]

92. Karami-Mohajeri, S.; Abdollahi, M. Toxic influence of organophosphate, carbamate, and organochlorine pesticides on cellular metabolism of lipids, proteins, and carbohydrates: A systematic review. Hum. Exp. Toxicol. 2011, 30, 1119-1140. [CrossRef] [PubMed]

93. Liang, Y.; Liu, D.; Zhan, J.; Luo, M.; Han, J.; Wang, P.; Zhou, Z. New insight into the mechanism of POP-induced obesity: Evidence from DDE-altered microbiota. Chemosphere 2020, 244, 125123. [CrossRef] [PubMed]

94. Bijland, S.; Rensen, P.C.; Pieterman, E.J.; Maas, A.C.; van der Hoorn, J.W.; van Erk, M.J.; Havekes, L.M.; van Dijk, K.W.; Chang, S.C.; Ehresman, D.J.; et al. Perfluoroalkyl sulfonates cause alkyl chain length-dependent hepatic steatosis and hypolipidemia mainly by impairing lipoprotein production in APOE*3-Leiden CETP mice. Toxicol. Sci. 2011, 123, 290-303. [CrossRef] [PubMed]

95. Zhao, W.; Zitzow, J.D.; Ehresman, D.J.; Chang, S.-C.; Butenhoff, J.L.; Forster, J.; Hagenbuch, B. $\mathrm{Na}^{+}$/Taurocholate Cotransporting Polypeptide and Apical Sodium-Dependent Bile Acid Transporter are Involved in the Disposition of Perfluoroalkyl Sulfonates in Humans and Rats. Toxicol. Sci. 2015, 146, 363-373. [CrossRef]

96. Steenland, K.; Tinker, S.; Shankar, A.; Ducatman, A. Association of perfluorooctanoic acid (PFOA) and perfluorooctane sulfonate (PFOS) with uric acid among adults with elevated community exposure to PFOA. Environ. Health Perspect. 2010, 118, 229-233. [CrossRef]

97. Hayden, M.R.; Tyagi, S.C. Uric acid: A new look at an old risk marker for cardiovascular disease, metabolic syndrome, and type 2 diabetes mellitus: The urate redox shuttle. Nutr. Metab. 2004, 1, 10. [CrossRef]

98. Dimitroula, H.V.; Hatzitolios, A.I.; Karvounis, H.I. The Role of Uric Acid in Stroke: The Issue Remains Unresolved. Neurologist. 2008, 14, 238-242. [CrossRef]

99. Haeusler, R.A.; Astiarraga, B.; Camastra, S.; Accili, D.; Ferrannini, E. Human insulin resistance is associated with increased plasma levels of 12a-hydroxylated bile acids. Diabetes 2013, 62, 4184-4191. [CrossRef]

100. Prawitt, J.; Caron, S.; Staels, B. Bile Acid Metabolism and the Pathogenesis of Type 2 Diabetes. Curr. Diabetes Rep. 2011, 11, 160. [CrossRef]

101. Zhang, L.; Rimal, B.; Nichols, R.G.; Tian, Y.; Smith, P.B.; Hatzakis, E.; Chang, S.C.; Butenhoff, J.L.; Peters, J.M.; Patterson, A.D. Perfluorooctane sulfonate alters gut microbiota-host metabolic homeostasis in mice. Toxicology 2020, 431, 152365. [CrossRef]

102. Petriello, M.C.; Hoffman, J.B.; Vsevolozhskaya, O.; Morris, A.J.; Hennig, B. Dioxin-like PCB 126 increases intestinal inflammation and disrupts gut microbiota and metabolic homeostasis. Environ. Pollut. 2018, 242, 1022-1032. [CrossRef] [PubMed]

103. Cheng, S.L.; Li, X.; Lehmler, H.-J.; Phillips, B.; Shen, D.; Cui, J.Y. Gut Microbiota Modulates Interactions Between Polychlorinated Biphenyls and Bile Acid Homeostasis. Toxicol. Sci. 2018, 166, 269-287. [CrossRef] [PubMed] 
104. Salihović, S.; Dickens, A.M.; Schoultz, I.; Fart, F.; Sinisalu, L.; Lindeman, T.; Halfvarson, J.; Orešič, M.; Hyötyläinen, T. Simultaneous determination of perfluoroalkyl substances and bile acids in human serum using ultra-high-performance liquid chromatography-tandem mass spectrometry. Anal. Bioanal. Chem. 2019. [CrossRef] [PubMed]

105. Jeanneret, F.; Tonoli, D.; Hochstrasser, D.; Saurat, J.-H.; Sorg, O.; Boccard, J.; Rudaz, S. Evaluation and identification of dioxin exposure biomarkers in human urine by high-resolution metabolomics, multivariate analysis and in vitro synthesis. Toxicol. Lett. 2016, 240, 22-31. [CrossRef]

106. Chiang, J.Y. Recent advances in understanding bile acid homeostasis. F1000Research 2017, 6, 2029. [CrossRef]

107. Buhrke, T.; Kruger, E.; Pevny, S.; Rossler, M.; Bitter, K.; Lampen, A. Perfluorooctanoic acid (PFOA) affects distinct molecular signalling pathways in human primary hepatocytes. Toxicology 2015, 333, 53-62. [CrossRef]

108. Iszatt, N.; Janssen, S.; Lenters, V.; Dahl, C.; Stigum, H.; Knight, R.; Mandal, S.; Peddada, S.; González, A.; Midtvedt, T.; et al. Environmental toxicants in breast milk of Norwegian mothers and gut bacteria composition and metabolites in their infants at 1 month. Microbiome 2019, 7, 34. [CrossRef]

109. Pan, Z.; Yuan, X.; Tu, W.; Fu, Z.; Jin, Y. Subchronic exposure of environmentally relevant concentrations of $\mathrm{F}-53 \mathrm{~B}$ in mice resulted in gut barrier dysfunction and colonic inflammation in a sex-independent manner. Environ. Pollut. 2019, 253, 268-277. [CrossRef]

110. Rude, K.M.; Keogh, C.E.; Gareau, M.G. The role of the gut microbiome in mediating neurotoxic outcomes to PCB exposure. Neurotoxicology 2019, 75, 30-40. [CrossRef]

111. De Aguiar Vallim, T.Q.; Tarling, E.J.; Edwards, P.A. Pleiotropic Roles of Bile Acids in Metabolism. Cell Metab. 2013, 17, 657-669. [CrossRef]

112. Wang, M.; Rang, O.; Liu, F.; Xia, W.; Li, Y.; Zhang, Y.; Lu, S.; Xu, S.J.M. A systematic review of metabolomics biomarkers for Bisphenol A exposure. Metabolomics 2018, 14, 45. [CrossRef] [PubMed]

113. Khan, A.; Park, H.; Lee, H.A.; Park, B.; Gwak, H.S.; Lee, H.-R.; Jee, S.H.; Park, Y.H. Elevated Metabolites of Steroidogenesis and Amino Acid Metabolism in Preadolescent Female Children with High Urinary Bisphenol A Levels: A High-Resolution Metabolomics Study. Toxicol. Sci. 2017, 160, 371-385. [CrossRef] [PubMed]

114. Alderete, T.L.; Jin, R.; Walker, D.I.; Valvi, D.; Chen, Z.; Jones, D.P.; Peng, C.; Gilliland, F.D.; Berhane, K.; Conti, D.V.; et al. Perfluoroalkyl substances, metabolomic profiling, and alterations in glucose homeostasis among overweight and obese Hispanic children: A proof-of-concept analysis. Environ. Int. 2019, 126, 445-453. [CrossRef] [PubMed]

115. Jin, R.; McConnell, R.; Catherine, C.; Xu, S.; Walker, D.I.; Stratakis, N.; Jones, D.P.; Miller, G.W.; Peng, C.; Conti, D.V.; et al. Perfluoroalkyl substances and severity of nonalcoholic fatty liver in Children: An untargeted metabolomics approach. Environ. Int. 2020, 134, 105220. [CrossRef] [PubMed]

116. Arneth, B.; Arneth, R.; Shams, M. Metabolomics of Type 1 and Type 2 Diabetes. Int. J. Mol. Sci. 2019, 20, 2467. [CrossRef]

117. Chuang, W.-H.; Arundhathi, A.; Lu, C.; Chen, C.-C.; Wu, W.-C.; Susanto, H.; Purnomo, J.D.T.; Wang, C.-H.J.M. Altered plasma acylcarnitine and amino acid profiles in type 2 diabetic kidney disease. Metabolomics 2016, 12, 108. [CrossRef]

118. Floegel, A.; Stefan, N.; Yu, Z.; Mühlenbruch, K.; Drogan, D.; Joost, H.-G.; Fritsche, A.; Häring, H.-U.; Hrabě de Angelis, M.; Peters, A.; et al. Identification of Serum Metabolites Associated With Risk of Type 2 Diabetes Using a Targeted Metabolomic Approach. Diabetes 2013, 62, 639-648. [CrossRef]

119. Gar, C.; Rottenkolber, M.; Prehn, C.; Adamski, J.; Seissler, J.; Lechner, A. Serum and plasma amino acids as markers of prediabetes, insulin resistance, and incident diabetes. Crit. Rev. Clin. Lab. Sci. 2018, 55, 21-32. [CrossRef]

120. Wang, X.; Liu, L.; Zhang, W.; Zhang, J.; Du, X.; Huang, Q.; Tian, M.; Shen, H. Serum metabolome biomarkers associate low-level environmental perfluorinated compound exposure with oxidative/nitrosative stress in humans. Environ. Pollut. 2017, 229, 168-176. [CrossRef]

121. Wang, Z.; Xu, X.; He, B.; Guo, J.; Zhao, B.; Zhang, Y.; Zhou, Z.; Zhou, X.; Zhang, R.; Abliz, Z. The impact of chronic environmental metal and benzene exposure on human urinary metabolome among Chinese children and the elderly population. Ecotoxicol. Environ. Saf. 2019, 169, 232-239. [CrossRef]

122. Wang, F.; Zhang, H.; Geng, N.; Ren, X.; Zhang, B.; Gong, Y.; Chen, J. A metabolomics strategy to assess the combined toxicity of polycyclic aromatic hydrocarbons (PAHs) and short-chain chlorinated paraffins (SCCPs). Environ. Pollut. 2018, 234, 572-580. [CrossRef] [PubMed] 
123. Liang, D.; Moutinho, J.L.; Golan, R.; Yu, T.; Ladva, C.N.; Niedzwiecki, M.; Walker, D.I.; Sarnat, S.E.; Chang, H.H.; Greenwald, R.; et al. Use of high-resolution metabolomics for the identification of metabolic signals associated with traffic-related air pollution. Environ. Int. 2018, 120, 145-154. [CrossRef] [PubMed]

124. Caserta, D.; Ciardo, F.; Bordi, G.; Guerranti, C.; Fanello, E.; Perra, G.; Borghini, F.; La Rocca, C.; Tait, S.; Bergamasco, B.; et al. Correlation of endocrine disrupting chemicals serum levels and white blood cells gene expression of nuclear receptors in a population of infertile women. Int. J. Endocrinol. 2013, 2013, 510703. [CrossRef] [PubMed]

125. Mu, X.; Huang, Y.; Li, J.; Yang, K.; Yang, W.; Shen, G.; Li, X.; Lei, Y.; Pang, S.; Wang, C.; et al. New insights into the mechanism of phthalate-induced developmental effects. Environ. Pollut. 2018, 241, 674-683. [CrossRef]

126. Xia, B.; Zhu, Q.; Zhao, Y.; Ge, W.; Zhao, Y.; Song, Q.; Zhou, Y.; Shi, H.; Zhang, Y. Phthalate exposure and childhood overweight and obesity: Urinary metabolomic evidence. Environ. Int. 2018, 121, 159-168. [CrossRef]

127. Jin, Y.; Wu, S.; Zeng, Z.; Fu, Z. Effects of environmental pollutants on gut microbiota. Environ. Pollut. 2017, 222, 1-9. [CrossRef]

128. Zhang, L.; Nichols, R.G.; Correll, J.; Murray, I.A.; Tanaka, N.; Smith, P.B.; Hubbard, T.D.; Sebastian, A.; Albert, I.; Hatzakis, E.; et al. Persistent Organic Pollutants Modify Gut Microbiota-Host Metabolic Homeostasis in Mice Through Aryl Hydrocarbon Receptor Activation. Environ. Health Perspect. 2015, 123, 679-688. [CrossRef]

129. Zhang, Y.; Keerthisinghe, T.P.; Han, Y.; Liu, M.; Wanjaya, E.R.; Fang, M. “Cocktail” of Xenobiotics at Human Relevant Levels Reshapes the Gut Bacterial Metabolome in a Species-Specific Manner. Environ. Sci. Technol. 2018, 52, 11402-11410. [CrossRef]

130. Yuan, X.; Pan, Z.; Jin, C.; Ni, Y.; Fu, Z.; Jin, Y. Gut microbiota: An underestimated and unintended recipient for pesticide-induced toxicity. Chemosphere 2019, 227, 425-434. [CrossRef]

131. Bi, Y.; Wang, W.; Xu, M.; Wang, T.; Lu, J.; Xu, Y.; Dai, M.; Chen, Y.; Zhang, D.; Sun, W.; et al. Diabetes Genetic Risk Score Modifies Effect of Bisphenol A Exposure on Deterioration in Glucose Metabolism. J. Clin. Endocrinol. Metab. 2016, 101, 143-150. [CrossRef]

132. Bodin, J.; Groeng, E.-C.; Andreassen, M.; Dirven, H.; Nygaard, U.C. Exposure to perfluoroundecanoic acid (PFUnDA) accelerates insulitis development in a mouse model of type 1 diabetes. Toxicol. Rep. 2016, 3, 664-672. [CrossRef]

133. Bodin, J.; Stene, L.C.; Nygaard, U.C. Can Exposure to Environmental Chemicals Increase the Risk of Diabetes Type 1 Development? Biomed Res. Int. 2015, 2015, 208947. [CrossRef]

134. Cui, J.; Fu, Y.; Lu, R.; Bi, Y.; Zhang, L.; Zhang, C.; Aschner, M.; Li, X.; Chen, R. Metabolomics analysis explores the rescue to neurobehavioral disorder induced by maternal PM2.5 exposure in mice. Ecotoxicol. Environ. Saf. 2019, 169, 687-695. [CrossRef] [PubMed]

135. Domazet, S.L.; Grøntved, A.; Timmermann, A.G.; Nielsen, F.; Jensen, T.K. Longitudinal Associations of Exposure to Perfluoroalkylated Substances in Childhood and Adolescence and Indicators of Adiposity and Glucose Metabolism 6 and 12 Years Later: The European Youth Heart Study. Diabetes Care 2016, 39, 1745-1751. [CrossRef] [PubMed]

136. Giulivo, M.; de Alda, M.L.; Capri, E.; Barcelo, D. Human exposure to endocrine disrupting compounds: Their role in reproductive systems, metabolic syndrome and breast cancer. A review. Environ. Res. 2016, 151, 251-264. [CrossRef] [PubMed]

137. Glynn, A.; Igra, A.M.; Sand, S.; Ilbäck, N.G.; Hellenäs, K.E.; Rosén, J.; Aspenström-Fagerlund, B. Are additive effects of dietary surfactants on intestinal tight junction integrity an overlooked human health risk?-A mixture study on Caco-2 monolayers. Food Chem. Toxicol. 2017, 106, 314-323. [CrossRef]

138. Govarts, E.; Iszatt, N.; Trnovec, T.; de Cock, M.; Eggesbø, M.; Palkovicova Murinova, L.; van de Bor, M.; Guxens, M.; Chevrier, C.; Koppen, G.; et al. Prenatal exposure to endocrine disrupting chemicals and risk of being born small for gestational age: Pooled analysis of seven European birth cohorts. Environ. Int. 2018, 115, 267-278. [CrossRef]

139. Granum, B.; Haug, L.S.; Namork, E.; Stolevik, S.B.; Thomsen, C.; Aaberge, I.S.; van Loveren, H.; Lovik, M.; Nygaard, U.C. Pre-natal exposure to perfluoroalkyl substances may be associated with altered vaccine antibody levels and immune-related health outcomes in early childhood. J. Immunotoxicol. 2013, 10, 373-379. [CrossRef]

140. Kharrazian, D. The Potential Roles of Bisphenol A (BPA) Pathogenesis in Autoimmunity. Autoimmune Dis. 2014, 2014, 743616. [CrossRef] 
141. Kim, S.; Eom, S.; Kim, H.J.; Lee, J.J.; Choi, G.; Choi, S.; Kim, S.; Kim, S.Y.; Cho, G.; Kim, Y.D.; et al. Association between maternal exposure to major phthalates, heavy metals, and persistent organic pollutants, and the neurodevelopmental performances of their children at 1 to 2 years of age- CHECK cohort study. Sci. Total Environ. 2018, 624, 377-384. [CrossRef]

142. Manzano-Salgado, C.B.; Casas, M.; Lopez-Espinosa, M.-J.; Ballester, F.; Iñiguez, C.; Martinez, D.; Costa, O.; Santa-Marina, L.; Pereda-Pereda, E.; Schettgen, T.; et al. Prenatal exposure to perfluoroalkyl substances and birth outcomes in a Spanish birth cohort. Environ. Int. 2017, 108, 278-284. [CrossRef] [PubMed]

143. Nelson, J.W.; Hatch, E.E.; Webster, T.F. Exposure to polyfluoroalkyl chemicals and cholesterol, body weight, and insulin resistance in the general U.S. population. Environ. Health Perspect. 2010, 118, 197-202. [CrossRef] [PubMed]

144. Nisticò, L.; Iafusco, D.; Galderisi, A.; Fagnani, C.; Cotichini, R.; Toccaceli, V.; Stazi, M.A.; the Study Group on Diabetes of the Italian Society of Pediatric Endocrinology and Diabetology. Emerging Effects of Early Environmental Factors over Genetic Background for Type 1 Diabetes Susceptibility: Evidence from a Nationwide Italian Twin Study. J. Clin. Endocrinol. Metab. 2012, 97, E1483-E1491. [CrossRef]

145. Predieri, B.; Iughetti, L.; Guerranti, C.; Bruzzi, P.; Perra, G.; Focardi, S.E. High Levels of Perfluorooctane Sulfonate in Children at the Onset of Diabetes. Int. J. Endocrinol. 2015, 2015, 234358. [CrossRef] [PubMed]

146. Sears, M.E.; Genuis, S.J. Environmental determinants of chronic disease and medical approaches: Recognition, avoidance, supportive therapy, and detoxification. J. Environ. Public Health 2012, 2012, 356798. [CrossRef]

147. Spratlen, M.J.; Grau-Perez, M.; Umans, J.G.; Yracheta, J.; Best, L.G.; Francesconi, K.; Goessler, W.; Bottiglieri, T.; Gamble, M.V.; Cole, S.A.; et al. Targeted metabolomics to understand the association between arsenic metabolism and diabetes-related outcomes: Preliminary evidence from the Strong Heart Family Study. Environ. Res. 2019, 168, 146-157. [CrossRef]

148. Timmermann, C.A.G.; Rossing, L.I.; Grøntved, A.; Ried-Larsen, M.; Dalgård, C.; Andersen, L.B.; Grandjean, P.; Nielsen, F.; Svendsen, K.D.; Scheike, T.; et al. Adiposity and Glycemic Control in Children Exposed to Perfluorinated Compounds. J. Clin. Endocrinol. Metab. 2014, 99, E608-E614. [CrossRef]

149. Yu, N.; Wei, S.; Li, M.; Yang, J.; Li, K.; Jin, L.; Xie, Y.; Giesy, J.P.; Zhang, X.; Yu, H. Effects of Perfluorooctanoic Acid on Metabolic Profiles in Brain and Liver of Mouse Revealed by a High-throughput Targeted Metabolomics Approach. Sci. Rep. 2016, 6, 23963. [CrossRef]

150. Zhang, L.; Hatzakis, E.; Nichols, R.G.; Hao, R.; Correll, J.; Smith, P.B.; Chiaro, C.R.; Perdew, G.H.; Patterson, A.D. Metabolomics Reveals that Aryl Hydrocarbon Receptor Activation by Environmental Chemicals Induces Systemic Metabolic Dysfunction in Mice. Environ. Sci. Technol. 2015, 49, 8067-8077. [CrossRef]

151. Carlsten, C. Synergistic Environmental Exposures and the Airways Capturing Complexity in Humans: An Underappreciated World of Complex Exposures. Chest 2018, 154, 918-924. [CrossRef]

152. Leite, D.F.B.; Morillon, A.-C.; Melo Júnior, E.F.; Souza, R.T.; McCarthy, F.P.; Khashan, A.; Baker, P.; Kenny, L.C.; Cecatti, J.G. Examining the predictive accuracy of metabolomics for small-for-gestational-age babies: A systematic review. BMJ Open 2019, 9, e031238. [CrossRef] [PubMed]

153. Maitre, L.; Villanueva, C.M.; Lewis, M.R.; Ibarluzea, J.; Santa-Marina, L.; Vrijheid, M.; Sunyer, J.; Coen, M.; Toledano, M.B. Maternal urinary metabolic signatures of fetal growth and associated clinical and environmental factors in the INMA study. BMC Med. 2016, 14, 177. [CrossRef] [PubMed]

154. Hellmuth, C.; Uhl, O.; Standl, M.; Demmelmair, H.; Heinrich, J.; Koletzko, B.; Thiering, E. Cord Blood Metabolome is Highly Associated with Birth Weight, but Less Predictive for Later Weight Development. Obes. Facts 2017, 10, 85-100. [CrossRef] [PubMed]

155. Lu, Y.P.; Reichetzeder, C.; Prehn, C.; Yin, L.H.; Yun, C.; Zeng, S.; Chu, C.; Adamski, J.; Hocher, B. Cord Blood Lysophosphatidylcholine 16: 1 is Positively Associated with Birth Weight. Cell. Physiol. Biochem. 2018, 45, 614-624. [CrossRef]

156. Rolle-Kampczyk, U.E.; Krumsiek, J.; Otto, W.; Röder, S.W.; Kohajda, T.; Borte, M.; Theis, F.; Lehmann, I.; von Bergen, M.J.M. Metabolomics reveals effects of maternal smoking on endogenous metabolites from lipid metabolism in cord blood of newborns. Metabolomics 2016, 12, 76. [CrossRef]

157. Meng, Z.; Tian, S.; Yan, J.; Jia, M.; Yan, S.; Li, R.; Zhang, R.; Zhu, W.; Zhou, Z. Effects of perinatal exposure to $\mathrm{BPA}, \mathrm{BPF}$ and BPAF on liver function in male mouse offspring involving in oxidative damage and metabolic disorder. Environ. Pollut. 2019, 247, 935-943. [CrossRef] 
158. Meng, Z.; Wang, D.; Liu, W.; Li, R.; Yan, S.; Jia, M.; Zhang, L.; Zhou, Z.; Zhu, W. Perinatal exposure to Bisphenol S (BPS) promotes obesity development by interfering with lipid and glucose metabolism in male mouse offspring. Environ. Res. 2019, 173, 189-198. [CrossRef]

159. Susiarjo, M.; Xin, F.; Stefaniak, M.; Mesaros, C.; Simmons, R.A.; Bartolomei, M.S. Bile Acids and Tryptophan Metabolism Are Novel Pathways Involved in Metabolic Abnormalities in BPA-Exposed Pregnant Mice and Male Offspring. Endocrinology 2017, 158, 2533-2542. [CrossRef]

160. Mamsen, L.S.; Jönsson, B.A.G.; Lindh, C.H.; Olesen, R.H.; Larsen, A.; Ernst, E.; Kelsey, T.W.; Andersen, C.Y. Concentration of perfluorinated compounds and cotinine in human foetal organs, placenta, and maternal plasma. Sci. Total Environ. 2017, 596-597, 97-105. [CrossRef]

161. Kishi, R.; Araki, A.; Minatoya, M.; Hanaoka, T.; Miyashita, C.; Itoh, S.; Kobayashi, S.; Ait Bamai, Y.; Yamazaki, K.; Miura, R.; et al. The Hokkaido Birth Cohort Study on Environment and Children's Health: Cohort profile-updated 2017. Environ. Health Prev. Med. 2017, 22, 46. [CrossRef]

162. Achenbach, P.; Bonifacio, E.; Koczwara, K.; Ziegler, A.-G. Natural History of Type 1 Diabetes. Diabetes 2005, 54, S25-S31. [CrossRef] [PubMed]

163. Starling, A.P.; Adgate, J.L.; Hamman, R.F.; Kechris, K.; Calafat, A.M.; Ye, X.; Dabelea, D. Perfluoroalkyl Substances during Pregnancy and Offspring Weight and Adiposity at Birth: Examining Mediation by Maternal Fasting Glucose in the Healthy Start Study. Environ. Health Perspect. 2017, 125, 067016. [CrossRef] [PubMed]

164. Ashley-Martin, J.; Dodds, L.; Arbuckle, T.E.; Bouchard, M.F.; Fisher, M.; Morriset, A.-S.; Monnier, P.; Shapiro, G.D.; Ettinger, A.S.; Dallaire, R.; et al. Maternal Concentrations of Perfluoroalkyl Substances and Fetal Markers of Metabolic Function and Birth Weight: The Maternal-Infant Research on Environmental Chemicals (MIREC) Study. Am. J. Epidemiol. 2017, 185, 185-193. [CrossRef] [PubMed]

165. Marks, K.J.; Cutler, A.J.; Jeddy, Z.; Northstone, K.; Kato, K.; Hartman, T.J. Maternal serum concentrations of perfluoroalkyl substances and birth size in British boys. Int. J. Hyg. Environ. Health 2019, 222, 889-895. [CrossRef] [PubMed]

166. Maisonet, M.; Terrell, M.L.; McGeehin, M.A.; Christensen, K.Y.; Holmes, A.; Calafat, A.M.; Marcus, M. Maternal concentrations of polyfluoroalkyl compounds during pregnancy and fetal and postnatal growth in British girls. Environ. Health Perspect. 2012, 120, 1432-1437. [CrossRef] [PubMed]

167. Kashino, I.; Sasaki, S.; Okada, E.; Matsuura, H.; Goudarzi, H.; Miyashita, C.; Okada, E.; Ito, Y.M.; Araki, A.; Kishi, R. Prenatal exposure to 11 perfluoroalkyl substances and fetal growth: A large-scale, prospective birth cohort study. Environ. Int. 2020, 136, 105355. [CrossRef] [PubMed]

168. Darrow, L.A.; Stein, C.R.; Steenland, K. Serum Perfluorooctanoic Acid and Perfluorooctane Sulfonate Concentrations in Relation to Birth Outcomes in the Mid-Ohio Valley, 2005-2010. Environ. Health Perspect. 2013, 121, 1207-1213. [CrossRef]

169. Kishi, R.; Nakajima, T.; Goudarzi, H.; Kobayashi, S.; Sasaki, S.; Okada, E.; Miyashita, C.; Itoh, S.; Araki, A.; Ikeno, T.; et al. The Association of Prenatal Exposure to Perfluorinated Chemicals with Maternal Essential and Long-Chain Polyunsaturated Fatty Acids during Pregnancy and the Birth Weight of Their Offspring: The Hokkaido Study. Environ. Health Perspect. 2015, 123, 1038-1045. [CrossRef]

170. Bach, C.C.; Bech, B.H.; Brix, N.; Nohr, E.A.; Bonde, J.P.E.; Henriksen, T.B. Perfluoroalkyl and polyfluoroalkyl substances and human fetal growth: A systematic review. Crit. Rev. Toxicol. 2015, 45, 53-67. [CrossRef]

171. Halldorsson, T.I.; Rytter, D.; Haug, L.S.; Bech, B.H.; Danielsen, I.; Becher, G.; Henriksen, T.B.; Olsen, S.F. Prenatal exposure to perfluorooctanoate and risk of overweight at 20 years of age: A prospective cohort study. Environ. Health Perspect. 2012, 120, 668-673. [CrossRef]

172. Fleisch, A.F.; Rifas-Shiman, S.L.; Mora, A.M.; Calafat, A.M.; Ye, X.; Luttmann-Gibson, H.; Gillman, M.W.; Oken, E.; Sagiv, S.K. Early-Life Exposure to Perfluoroalkyl Substances and Childhood Metabolic Function. Environ. Health Perspect. 2017, 125, 481-487. [CrossRef] [PubMed]

173. Misra, B.B.; Misra, A. The chemical exposome of type 2 diabetes mellitus: Opportunities and challenges in the omics era. Diabetes Metab. Syndr. 2020, 14, 23-38. [CrossRef] [PubMed]

174. Rantakokko, P.; Männistö, V.; Airaksinen, R.; Koponen, J.; Viluksela, M.; Kiviranta, H.; Pihlajamäki, J. Persistent organic pollutants and non-alcoholic fatty liver disease in morbidly obese patients: A cohort study. Environ. Health 2015, 14, 79. [CrossRef] [PubMed] 
175. Sunderland, E.M.; Hu, X.C.; Dassuncao, C.; Tokranov, A.K.; Wagner, C.C.; Allen, J.G. A review of the pathways of human exposure to poly- and perfluoroalkyl substances (PFASs) and present understanding of health effects. J. Expo. Sci. Environ. Epidemiol. 2019, 29, 131-147. [CrossRef] [PubMed]

176. He, X.; Liu, Y.; Xu, B.; Gu, L.; Tang, W. PFOA is associated with diabetes and metabolic alteration in US men: National Health and Nutrition Examination Survey 2003-2012. Sci. Total Environ. 2018, 625, 566-574. [CrossRef]

177. Cardenas, A.; Gold, D.R.; Hauser, R.; Kleinman, K.P.; Hivert, M.-F.; Calafat, A.M.; Ye, X.; Webster, T.F.; Horton, E.S.; Oken, E. Plasma Concentrations of Per- and Polyfluoroalkyl Substances at Baseline and Associations with Glycemic Indicators and Diabetes Incidence among High-Risk Adults in the Diabetes Prevention Program Trial. Environ. Health Perspect. 2017, 125, 107001. [CrossRef]

178. Bach, J.F. The effect of infections on susceptibility to autoimmune and allergic diseases. N. Engl. J. Med. 2002, 347, 911-920. [CrossRef]

179. Patterson, C.C.; Dahlquist, G.G.; Gyürüs, E.; Green, A.; Soltész, G. Incidence trends for childhood type 1 diabetes in Europe during 1989-2003 and predicted new cases 2005-20: A multicentre prospective registration study. Lancet 2009, 373, 2027-2033. [CrossRef]

180. Atkinson, M.A.; Eisenbarth, G.S.; Michels, A.W. Type 1 diabetes. Lancet 2014, 383, 69-82. [CrossRef]

181. Knip, M.; Veijola, R.; Virtanen, S.M.; Hyöty, H.; Vaarala, O.; Åkerblom, H.K. Environmental triggers and determinants of type 1 diabetes. Diabetes 2005, 54, S125-S136. [CrossRef]

182. Harjutsalo, V.; Sund, R.; Knip, M.; Groop, P.H. Incidence of type 1 diabetes in Finland. JAMA 2013, 310, 427-428. [CrossRef] [PubMed]

183. Kaikkonen, R.; Mäki, P.; Hakulinen-Viitanen, T.; Markkula, J.; Wikström, K.; Ovaskainen, M.-L.; Virtanen, S.; Laatikainen, T. Health and Well-Being Inequalities Among Children and Their Families; National Institute for Health and Wellfare: Helsinki, Finland, 2012.

184. Corsini, E.; Luebke, R.W.; Germolec, D.R.; DeWitt, J.C. Perfluorinated compounds: Emerging POPs with potential immunotoxicity. Toxicol. Lett. 2014, 230, 263-270. [CrossRef] [PubMed]

185. National Toxicology Program. Systematic Review of Immunotoxicity Associated with Exposure to PFOA or PFOS; National Toxicology Program: Research Triangle Park, NC, USA, 2016. Available online: https: //ntp.niehs.nih.gov/ntp/ohat/pfoa_pfos/pfoa_pfosmonograph_508.pdf (accessed on 8 November 2020).

186. Liu, S.; Yin, N.; Faiola, F. PFOA and PFOS Disrupt the Generation of Human Pancreatic Progenitor Cells. Environ. Sci. Technol. Lett. 2018, 5, 237-242. [CrossRef]

187. Conway, B.; Innes, K.E.; Long, D. Perfluoroalkyl substances and beta cell deficient diabetes. J. Diabetes Complicat. 2016, 30, 993-998. [CrossRef] [PubMed]

188. DeWitt, J.C.; Shnyra, A.; Badr, M.Z.; Loveless, S.E.; Hoban, D.; Frame, S.R.; Cunard, R.; Anderson, S.E.; Meade, B.J.; Peden-Adams, M.M.; et al. Immunotoxicity of Perfluorooctanoic Acid and Perfluorooctane Sulfonate and the Role of Peroxisome Proliferator-Activated Receptor Alpha. Crit. Rev. Toxicol. 2009, 39, 76-94. [CrossRef]

189. Salo, H.M.; Koponen, J.; Kiviranta, H.; Rantakokko, P.; Honkanen, J.; Härkönen, T.; Ilonen, J.; Virtanen, S.M.; Tillmann, V.; Knip, M.; et al. No evidence of the role of early chemical exposure in the development of $\beta$-cell autoimmunity. Env. Sci. Pollu. Res. Int. 2018. [CrossRef]

190. Fang, X.; Zhang, L.; Feng, Y.; Zhao, Y.; Dai, J. Immunotoxic Effects of Perfluorononanoic Acid on BALB/c Mice. Toxicol. Sci. 2008, 105, 312-321. [CrossRef]

191. Oresic, M.; Simell, S.; Sysi-Aho, M.; Nanto-Salonen, K.; Seppanen-Laakso, T.; Parikka, V.; Katajamaa, M.; Hekkala, A.; Mattila, I.; Keskinen, P.; et al. Dysregulation of lipid and amino acid metabolism precedes islet autoimmunity in children who later progress to type 1 diabetes. J. Exp. Med. 2008, 205, 2975-2984. [CrossRef]

192. Overgaard, A.J.; Kaur, S.; Pociot, F. Metabolomic Biomarkers in the Progression to Type 1 Diabetes. Curr. Diabetes Rep. 2016, 16, 127. [CrossRef]

193. Johnson, R.K.; Vanderlinden, L.; DeFelice, B.C.; Kechris, K.; Uusitalo, U.; Fiehn, O.; Sontag, M.; Crume, T.; Beyerlein, A.; Lernmark, A.; et al. Metabolite-related dietary patterns and the development of islet autoimmunity. Sci. Rep. 2019, 9, 14819. [CrossRef]

194. Oresic, M.; Gopalacharyulu, P.; Mykkanen, J.; Lietzen, N.; Makinen, M.; Nygren, H.; Simell, S.; Simell, V.; Hyoty, H.; Veijola, R.; et al. Cord serum lipidome in prediction of islet autoimmunity and type 1 diabetes. Diabetes 2013, 62, 3268-3274. [CrossRef] [PubMed] 
195. La Torre, D.; Seppanen-Laakso, T.; Larsson, H.E.; Hyotylainen, T.; Ivarsson, S.A.; Lernmark, A.; Oresic, M.; DiPi, S.S.G. Decreased cord-blood phospholipids in young age-at-onset type 1 diabetes. Diabetes 2013, 62, 3951-3956. [CrossRef] [PubMed]

196. Alkotob, S.S.; Cannedy, C.; Harter, K.; Movassagh, H.; Paudel, B.; Prunicki, M.; Sampath, V.; Schikowski, T.; Smith, E.; Zhao, Q.; et al. Advances and novel developments in environmental influences on the development of atopic diseases. Allergy 2020. [CrossRef]

197. Eguiluz-Gracia, I.; Mathioudakis, A.G.; Bartel, S.; Vijverberg, S.J.H.; Fuertes, E.; Comberiati, P.; Cai, Y.S.; Tomazic, P.V.; Diamant, Z.; Vestbo, J.; et al. The need for clean air: The way air pollution and climate change affect allergic rhinitis and asthma. Allergy 2020, 75, 2170-2184. [CrossRef]

198. Guarnieri, M.; Balmes, J.R. Outdoor air pollution and asthma. Lancet 2014, 383, 1581-1592. [CrossRef]

199. Burney, P.; Amaral, A.F.S. Air pollution and chronic airway disease: Is the evidence always clear? Lancet 2019, 394, 2198-2200. [CrossRef]

200. Miller, R.L.; Peden, D.B. Environmental effects on immune responses in patients with atopy and asthma. J. Allergy Clin. Immunol. 2014, 134, 1001-1008. [CrossRef]

201. Cecchi, L.; D'Amato, G.; Annesi-Maesano, I. External exposome and allergic respiratory and skin diseases. J. Allergy Clin. Immunol. 2018, 141, 846-857. [CrossRef]

202. Burbank, A.J.; Sood, A.K.; Kesic, M.J.; Peden, D.B.; Hernandez, M.L. Environmental determinants of allergy and asthma in early life. J. Allergy Clin. Immunol. 2017, 140, 1-12. [CrossRef]

203. Kantor, R.; Silverberg, J.I. Environmental risk factors and their role in the management of atopic dermatitis. Expert Rev. Clin. Immunol. 2017, 13, 15-26. [CrossRef]

204. Kim, D.; Seo, S.; Min, S.; Simoni, Z.; Kim, S.; Kim, M. A Closer Look at the Bivariate Association between Ambient Air Pollution and Allergic Diseases: The Role of Spatial Analysis. Int. J. Environ. Res. Public Health 2018, 15, 1625. [CrossRef] [PubMed]

205. Carlsten, C.; Rider, C.F. Traffic-related air pollution and allergic disease: An update in the context of global urbanization. Curr. Opin. Allergy Clin. Immunol. 2017, 17, 85-89. [CrossRef] [PubMed]

206. Lee, K.K.; Bing, R.; Kiang, J.; Bashir, S.; Spath, N.; Stelzle, D.; Mortimer, K.; Bularga, A.; Doudesis, D.; Joshi, S.S.; et al. Adverse health effects associated with household air pollution: A systematic review, meta-analysis, and burden estimation study. Lancet Glob. Health 2020, 8, e1427-e1434. [CrossRef]

207. Bowatte, G.; Lodge, C.; Lowe, A.J.; Erbas, B.; Perret, J.; Abramson, M.J.; Matheson, M.; Dharmage, S.C. The influence of childhood traffic-related air pollution exposure on asthma, allergy and sensitization: A systematic review and a meta-analysis of birth cohort studies. Allergy 2015, 70, 245-256. [CrossRef]

208. Lloyd, C.M.; Marsland, B.J. Lung Homeostasis: Influence of Age, Microbes, and the Immune System. Immunity 2017, 46, 549-561. [CrossRef]

209. Agache, I.; Miller, R.; Gern, J.E.; Hellings, P.W.; Jutel, M.; Muraro, A.; Phipatanakul, W.; Quirce, S.; Peden, D. Emerging concepts and challenges in implementing the exposome paradigm in allergic diseases and asthma: A Practall document. Allergy 2019, 74, 449-463. [CrossRef]

210. Li, H.; Ryu, M.H.; Rider, C.F.; Tse, W.; Clifford, R.L.; Aristizabal, M.J.; Wen, W.; Carlsten, C. Predominant DNMT and TET mediate effects of allergen on the human bronchial epithelium in a controlled air pollution exposure study. J. Allergy Clin. Immunol. 2020. [CrossRef]

211. Maestre-Batlle, D.; Huff, R.D.; Schwartz, C.; Alexis, N.E.; Tebbutt, S.J.; Turvey, S.; Bolling, A.K.; Carlsten, C. Dibutyl Phthalate Augments Allergen-induced Lung Function Decline and Alters Human Airway Immunology. A Randomized Crossover Study. Am. J. Respir Crit. Care Med. 2020, 202, 672-680. [CrossRef]

212. Murrison, L.B.; Brandt, E.B.; Myers, J.B.; Hershey, G.K.K. Environmental exposures and mechanisms in allergy and asthma development. J. Clin. Investig. 2019, 129, 1504-1515. [CrossRef]

213. Schultz, E.S.; Litonjua, A.A.; Melen, E. Effects of Long-Term Exposure to Traffic-Related Air Pollution on Lung Function in Children. Curr. Allergy Asthma Rep. 2017, 17, 41. [CrossRef]

214. Shin, S.; Bai, L.; Burnett, R.T.; Kwong, J.C.; Hystad, P.; van Donkelaar, A.; Lavigne, E.; Weichenthal, S.; Copes, R.; Martin, R.V.; et al. Air Pollution as a Risk Factor for Incident COPD and Asthma: 15-Year Population-Based Cohort Study. Am. J. Respir Crit. Care Med. 2020. [CrossRef] [PubMed]

215. Granum, B.; Oftedal, B.; Agier, L.; Siroux, V.; Bird, P.; Casas, M.; Warembourg, C.; Wright, J.; Chatzi, L.; de Castro, M.; et al. Multiple environmental exposures in early-life and allergy-related outcomes in childhood. Environ. Int. 2020, 144, 106038. [CrossRef] [PubMed] 
216. Ait Bamai, Y.; Miyashita, C.; Araki, A.; Nakajima, T.; Sasaki, S.; Kishi, R. Effects of prenatal di(2-ethylhexyl) phthalate exposure on childhood allergies and infectious diseases: The Hokkaido Study on Environment and Children's Health. Sci. Total Environ. 2018, 618, 1408-1415. [CrossRef] [PubMed]

217. Gascon, M.; Casas, M.; Morales, E.; Valvi, D.; Ballesteros-Gomez, A.; Luque, N.; Rubio, S.; Monfort, N.; Ventura, R.; Martinez, D.; et al. Prenatal exposure to bisphenol A and phthalates and childhood respiratory tract infections and allergy. J. Allergy Clin. Immunol. 2015, 135, 370-378. [CrossRef] [PubMed]

218. EFSA Panel on Contaminants in the Food Chain (EFSA CONTAM, Panel); Schrenk, D.; Bignami, M.; Bodin, L.; Chipman, J.K.; Del Mazo, J.; Grasl-Kraupp, B.; Hogstrand, C.; Hoogenboom, L.R.; Leblanc, J.C.; et al. Risk to human health related to the presence of perfluoroalkyl substances in food. Efsa J. 2020, 18, e06223. [CrossRef]

219. Jackson-Browne, M.S.; Eliot, M.; Patti, M.; Spanier, A.J.; Braun, J.M. PFAS (per- and polyfluoroalkyl substances) and asthma in young children: NHANES 2013-2014. Int. J. Hyg. Environ. Health 2020, 229, 113565. [CrossRef] [PubMed]

220. Luo, Y.; Deji, Z.; Huang, Z. Exposure to perfluoroalkyl substances and allergic outcomes in children: A systematic review and meta-analysis. Environ. Res. 2020, 191, 110145. [CrossRef]

221. Moran, T.P. The External Exposome and Food Allergy. Curr. Allergy Asthma Rep. 2020, 20, 37. [CrossRef]

222. Savage, J.H.; Matsui, E.C.; Wood, R.A.; Keet, C.A. Urinary levels of triclosan and parabens are associated with aeroallergen and food sensitization. J. Allergy Clin. Immunol. 2012, 130, 453-460. [CrossRef]

223. Bertelsen, R.J.; Longnecker, M.P.; Lovik, M.; Calafat, A.M.; Carlsen, K.H.; London, S.J.; Lodrup Carlsen, K.C. Triclosan exposure and allergic sensitization in Norwegian children. Allergy 2013, 68, 84-91. [CrossRef]

224. Lee-Sarwar, K.; Hauser, R.; Calafat, A.M.; Ye, X.; O'Connor, G.T.; Sandel, M.; Bacharier, L.B.; Zeiger, R.S.; Laranjo, N.; Gold, D.R.; et al. Prenatal and early-life triclosan and paraben exposure and allergic outcomes. J. Allergy Clin. Immunol. 2018, 142, 269-278. [CrossRef] [PubMed]

225. Herberth, G.; Pierzchalski, A.; Feltens, R.; Bauer, M.; Roder, S.; Olek, S.; Hinz, D.; Borte, M.; von Bergen, M.; Lehmann, I.; et al. Prenatal phthalate exposure associates with low regulatory T-cell numbers and atopic dermatitis in early childhood: Results from the LINA mother-child study. J. Allergy Clin. Immunol. 2017, 139, 1376-1379. [CrossRef]

226. Podlecka, D.; Gromadzinska, J.; Mikolajewska, K.; Fijalkowska, B.; Stelmach, I.; Jerzynska, J. Longitudinal effect of phthalates exposure on allergic diseases in children. Ann. Allergy Asthma Immunol. 2020, 125, 84-89. [CrossRef]

227. Renz, H.; Skevaki, C. Early life microbial exposures and allergy risks: Opportunities for prevention. Nat. Rev. Immunol. 2020. [CrossRef] [PubMed]

228. Yu, J.E.; Mallapaty, A.; Miller, R.L. It's not just the food you eat: Environmental factors in the development of food allergies. Environ. Res. 2018, 165, 118-124. [CrossRef] [PubMed]

229. Rappaport, S.M. Genetic Factors Are Not the Major Causes of Chronic Diseases. PLoS ONE 2016, 11, e0154387. [CrossRef]

Publisher's Note: MDPI stays neutral with regard to jurisdictional claims in published maps and institutional affiliations.

(C) 2020 by the authors. Licensee MDPI, Basel, Switzerland. This article is an open access article distributed under the terms and conditions of the Creative Commons Attribution (CC BY) license (http://creativecommons.org/licenses/by/4.0/). 